\title{
Proteomics Shows New Faces for the Old Penicillin Producer Penicillium chrysogenum
}

\author{
Carlos Barreiro, Juan F. Martín, and Carlos García-Estrada \\ Proteomics Service of INBIOTEC, Instituto de Biotecnología de León (INBIOTEC), Parque Científico de León, Avenida. Real, no. 1, \\ 24006 León, Spain \\ Correspondence should be addressed to Carlos Barreiro, c.barreiro@unileon.es
}

Received 2 June 2011; Revised 30 September 2011; Accepted 14 October 2011

Academic Editor: Tanya Parish

Copyright ( 92012 Carlos Barreiro et al. This is an open access article distributed under the Creative Commons Attribution License, which permits unrestricted use, distribution, and reproduction in any medium, provided the original work is properly cited.

Fungi comprise a vast group of microorganisms including the Ascomycota (majority of all described fungi), the Basidiomycota (mushrooms or higher fungi), and the Zygomycota and Chytridiomycota (basal or lower fungi) that produce industrially interesting secondary metabolites, such as $\beta$-lactam antibiotics. These compounds are one of the most commonly prescribed drugs world-wide. Since Fleming's initial discovery of Penicillium notatum 80 years ago, the role of Penicillium as an antimicrobial source became patent. After the isolation of Penicillium chrysogenum NRRL 1951 six decades ago, classical mutagenesis and screening programs led to the development of industrial strains with increased productivity (at least three orders of magnitude). The new "omics" era has provided the key to understand the underlying mechanisms of the industrial strain improvement process. The review of different proteomics methods applied to P. chrysogenum has revealed that industrial modification of this microorganism was a consequence of a careful rebalancing of several metabolic pathways. In addition, the secretome analysis of $P$. chrysogenum has opened the door to new industrial applications for this versatile filamentous fungus.

\section{Introduction: Evolution of Fungi in Penicillin Production}

Life comprises three domains: the bacteria, the archaea, and the eukaryota. Within the last one, the fungi kingdom forms a monophyletic group of the eukaryotic crown group, which collects the largest group of organisms [1]. Fungi consist of a heterogeneous group including yeasts, moulds, and mushrooms characterized by their lack of photosynthetic pigment and their chitinous cell wall [2]. Hawksworth and Rossman $[3,4]$ described that the number of fungal species ranged between 72,000 and 120,000, which supposes less than $10 \%$ of the theoretically estimated 1.5 million existing fungal species. In contrast, when environmental samples based on metagenomics data are evaluated, the species number increases to as high as 3.5 million [5]. The discovery of the new fungal species described along the last years was evaluated by Hibbett and coworkers [6], which averages 223 species per year, mostly Ascomycota. These data present a huge number of unrecognized and unidentified fungal species (more than $90 \%$ ), which could be discovered in associations with plants, insects, and animals, as lichen-forming fungi or in undisturbed areas [4].

Traditionally, the four main fungal phyla were Ascomycota (majority of all described fungi) and Basidiomycota, which embody the mushrooms or higher fungi, and the Zygomycota and Chytridiomycota, which represent the basal or lower fungi. The first three phyla theoretically diverged from the last one (Chytridiomycota) approximately 550 million years ago $[1,7,8]$. This was an evolutionary step previous to the land invasion of the plants. The fungal taxonomy is in continuous movement; thus, Zygomycota has been replaced by several subphyla [9], and the arbuscular mycorrhizal fungi Glomeromycota has been included as a new phylum [10]. This evolution of the fungi and fungal-like microorganisms can be observed in the complex phylogenetic tree based on a Bayesian inference analysis reviewed by Voigt and Kirk [8].

The fungal environmental impact is remarkable due to the central role played in the organic matter decomposition process because of their ability to degrade recalcitrant compounds such as lignin; thereby the organic material utilization is enhanced by the microbial community. In addition, 
some species are involved in disease interactions with humans, plants, or animals, either by means of their direct action as disease agents or through the production of secondary metabolites (e.g., host-specific toxins). Related to this, filamentous fungi produce a diverse array of secondary metabolites and enzymes [11], which have a tremendous impact on society because they are exploited for their antibiotic (penicillins, cephalosporins, etc.) or pharmaceutical (cyclosporin and other immunosuppressants) activities and their industrial applications in white biotechnology (beverage industries). Therefore, fungi are the second most important group (after Actinobacteria) of secondary metabolites producers with industrial application [12].

Among secondary metabolites, antibiotics (and more precisely $\beta$-lactam antibiotics) are especially relevant. The discovery of $\beta$-lactam antibiotics is one of the most significant milestones of the human history and entailed a revolution in modern chemotheraphy. Members of this family of antibiotics are commonly prescribed due to their high activity and low toxicity and have helped medicine to reduce dramatically the mortality rate. The history of these compounds started up in 1928 after Sir Alexander Fleming's accidental discovery of the antimicrobial activity generated by a fungus culture contaminating a Petri dish cultured with Staphylococcus sp. Fleming, who worked at the St. Mary's Hospital in London, initially identified the mould responsible for the antibacterial effect as Penicillium rubrum [13]. However, it was not until 1932 when the Fleming's isolate was correctly identified as Penicillium notatum and the active compound inhibiting the bacterial growth was dubbed penicillin [14]. Fleming did not extend his work to clinical study due to the low amounts and instability of the penicillin purified from culture broths. It was in 1940 when a group of workers from the Sir William Dunn School of Pathology at Oxford University (H. W. Florey, E. B. Chain, N. Heatley, C. M. Fletcher, A. D. Gardner, M. A. Jennings, J. Orr-Ewing, A. G. Sanders, and E. Abraham) were able to undertake detailed studies on penicillin [15]. However, massive production could not be accomplished in England due to World War II. Therefore, Florey and Heatley went to the United States in June 1941 and convinced the U.S. Department of Agriculture (USDA) and several pharmaceutical firms (Charles Pfizer and Co., E. R. Squibb and Sons, and Merck and Co., among others) to produce penicillin [16]. Heatley remained for a period at the Northern Regional Research Laboratory of the USDA, Peoria, Illinois, USA. The isolation of new strains of Penicillium chrysogenum, industrial improvement programs (see below), and medium modifications favored the development of penicillin high-producing strains. The tremendous cooperative effort among universities and industrial laboratories in England and the United States during the war led to multiple large-scale clinical trials to treat those wounded in battle in England and in the United States during 1942 and 1943 [16]. In 1945, Ernst B. Chain, Howard W. Florey, and Sir Alexander Fleming were awarded with the Nobel Prize for Physiology and Medicine. A year later, penicillin was finally available in the open market.

Since the early days of penicillin development, it was rather clear that several different penicillins were being produced, depending on the composition of the medium, the fungal strain, and the fermentation conditions. Penicillins contain a bicyclic "penam" nucleus formed by fused $\beta$-lactam and sulphur-containing thiazolidine rings and an acyl side chain bound to the amino group at C-6. The side chain depends on the precursors present in the culture medium. Side chain attachment is relatively nonspecific, and therefore, natural penicillins, such as penicillin F (3-hexenoic as side chain), and $\mathrm{K}$ (octanoic acid as side chain), are synthesized under natural conditions. However, feeding the cultivation media with phenylacetic or phenoxyacetic acids directs the biosynthesis mainly towards benzylpenicillin (penicillin G) or phenoxymethylpenicillin (penicillin V), respectively. Biosynthesis, regulation, and evolution of the penicillin pathway have been reviewed extensively [17-19].

Another important milestone that opened a new era of chemotherapy was the detection and isolation of 6-aminopenicillanic acid (6-APA) in fermented broths in the decade of 1950s [20-23]. This penicillin precursor is the basis of semisynthetic penicillins, which are achieved through the addition of different side chains to 6-APA by a chemical process [24].

\section{Classical Strain Improvement and Molecular Genomic-Transcriptomic Basis of the Increased Penicillin Productivity}

One of the main problems that researchers initially had to face was the low penicillin titers (about 2 i.u. (international units) $/ \mathrm{mL}$ or $1.2 \mu \mathrm{g} / \mathrm{mL}$ ) produced by the original Fleming's P. notatum strain (NRRL 1249B21). This, together with the increasing demand of antibiotics derived from World War II and subsequent conflicts during the 20th century, led scientists to isolate new strains with more productivity (Figure 1). Thus, the strain improvement began in 1943 after the isolation of $P$. chrysogenum NRRL 1951 from a mouldy cantaloupe in a local market in Peoria, IL, USA $[25,26]$. This strain was more suitable than $P$. notatum for penicillin production in submerged cultures $(60 \mu \mathrm{g} / \mathrm{mL})$. Selection of single spores allowed the isolation of the higher-producing lineage NRRL 1951-B25, which produced up to $150 \mu \mathrm{g} / \mathrm{mL}$ (250 i.u./mL). This strain was X-ray treated by Demerec at the Carnegie Institution (Cold Spring Harbor, NY, USA) giving rise to the X-1612 mutant, which yielded $300 \mu \mathrm{g} / \mathrm{mL}$ of penicillin. This strain was mutated by $275 \mathrm{~nm}$ ultraviolet irradiation of spores at the University of Wisconsin, and the Q-176 mutant was obtained. It was tested in 300-liter fermentors, yielding over $550 \mu \mathrm{g} / \mathrm{mL}$ (900 i.u./mL) [27]. This strain represents the origin of the Wisconsin family of superior strains, some producing over $1800 \mu \mathrm{g} / \mathrm{mL}$ (3000 i.u./mL) [28]. After ultraviolet mutagenesis of strain Q-176, the pigmentless strain BL3D10 was obtained. This was desirable due to commercial purposes, since extraction of the yellow pigment produced naturally by $P$. chrysogenum gave rise to antibiotic losses during the purification process. Therefore, this strain was selected to produce directly the white commercial product although it involved a $25 \%$ reduction in penicillin yield [28]. The BL3-D10 strain was subjected to successive colony selection 


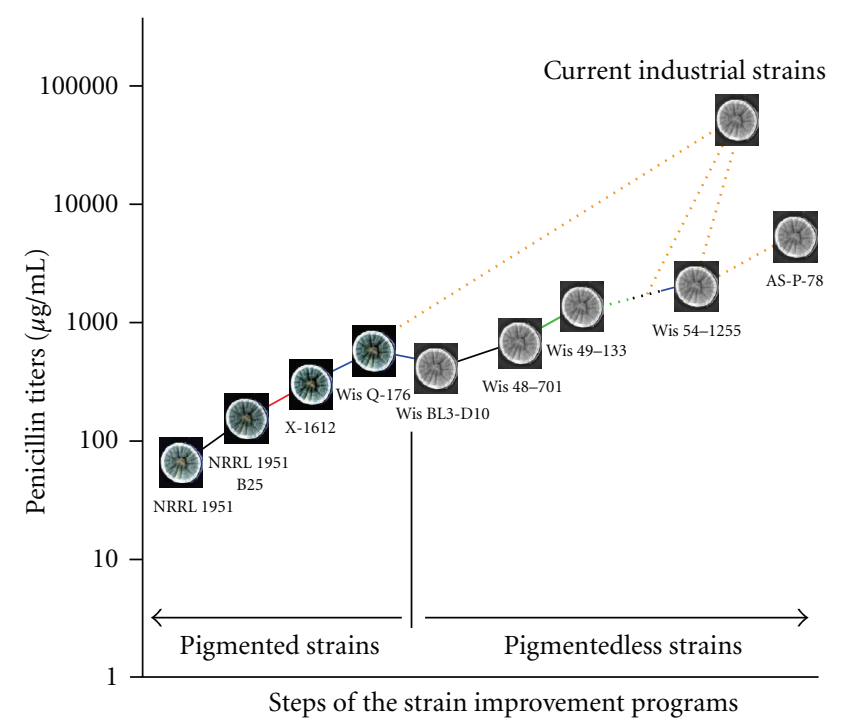

$\begin{array}{ll}\text { - Selection } & - \text { Nitrogen mustard } \\ \text { - X-ray } & \text { Unknown treatments } \\ \text { Ultraviolet irradiation } & \text { Dotted lines represent several steps }\end{array}$

FIGURE 1: Scheme showing the industrial strain improvement program of P. chrysogenum, Barreiro et al., 2011.

rounds without mutagenesis to stabilize the mutant strains. In this way, 47-638, 47-1564, and 48-701 were obtained. The $48-701$ strain produced around $650 \mu \mathrm{g} / \mathrm{mL}$ of penicillin and was mutated with nitrogen mustard, thus giving rise to the Wisconsin 49-133 strain. This strain represented the greatest single improvement among the Wisconsin pigmentless series, with penicillin yields $100 \%$ above that of the $48-701$ parent, only $50 \%$ as much mycelium, and an "exceptionally efficient utilization of phenylacetic acid" [29]. After several steps of nitrogen mustard mutagenesis followed by several steps of selection and one step of ultraviolet irradiation, the improved-producer Wisconsin 54-1255 was obtained and became the laboratory reference strain $[23,30,31]$. Besides the University of Wisconsin, some companies developed their own industrial strain improvement programs in order to obtain penicillin high-producer strains, but few data are available about these programs. For example, Panlabs Inc. (Taiwan) started the program with strains P1 and P2, which are derived from the Q-176 strain [32], DSM (The Netherlands) developed the DS04825 strain from the Wisconsin 54-1255 strain [33], Wyeth Lab (West Chester, PA, USA) developed the M strains (obtained from the Wisconsin 51-20 strain, one of the ancestors of Wisconsin 54-1255), and Antibioticos S.A. (Spain) produced the AS-P-78, AS-P99, and E1 strains from the Wisconsin family [34] (Figure 1). Overproducer mutants currently used for the industrial production of penicillin can reach titers of more than $50 \mathrm{mg} / \mathrm{mL}$ (83300 i.u./mL) in fed-batch cultures [32, 35].

As a consequence of the strain improvement programs, numerous modifications leading to impressive penicillin titers were introduced in $P$. chrysogenum. Some were characterized in detail, such as the phenomenon of amplification that occurs in the genomic region containing the three penicillin biosynthetic genes, $p c b A B, p c b C$, and $p e n D E$ (Figure 2(a)). These genes are arranged in a single cluster located on a DNA region present as a single copy in the genome of the wildtype NRRL 1951 and Wisconsin 54-1255 strains. This region undergoes tandem amplification in penicillin overproducing strains, giving rise to several copies of the biosynthetic gene cluster in those strains $[34,36]$. Hence, the AS-P-78 strain was reported to contain 5 to 6 copies, the E1 strain 12 to 14 copies [34], and the DS0485 strain 5 to 6 copies [37]. The mechanism of gene amplification is intriguing; it has been suggested that the conserved hexanucleotides located at the borders of the amplified region may be hot spots for site-specific recombination after mutagenesis [34]. It is noteworthy that the amplified region contains other ORFs in addition to the three biosynthetic genes $[37,38]$. Since these ORFs are amplified together with the penicillin biosynthetic cluster, a role in penicillin biosynthesis, regulation or secretion might be expected for those ORFs. However, it was demonstrated that the role of those ORFs was not essential for penicillin biosynthesis (although they may contribute to high penicillin production), since the presence of the three penicillin biosynthetic enzymes alone was sufficient to restore $\beta$-lactam synthesis in a mutant lacking the complete region $[37,39]$. No penicillin pathway-specific regulators have been found in the genome region that contains the penicillin gene cluster, and the biosynthesis of this antibiotic is controlled by global regulators, such as LaeA [40], the velvet complex [41], or StuA [42]. Other genes encoding enzymes important for the biosynthesis of penicillin are also absent from the amplified region. This is the case of the ppt gene encoding the phosphopantetheinyl transferase that posttranslationally activates the $\delta$-(L$\alpha$-aminoadipyl)-L-cysteinyl-D-valine synthetase (the first enzyme of the penicillin biosynthetic pathway) [43], or the phl gene encoding the phenylacetyl-CoA ligase, which activates the aromatic side chain of benzylpenicillin [44]. Interestingly, the amplification of either the laeA, $p p t$, or $p h l$ genes gave rise to increased penicillin titers $[40,43,44]$.

Although high-producing strains contain several copies of the penicillin cluster, it has been reported that penicillin production does not follow a linear correlation with the biosynthetic gene copy number, the transcript, or enzyme levels [36, 45-47], indicating that other modifications are also playing an important role. One of those modifications has also been characterized in detail and is related to the catabolism of phenylacetic acid (the benzylpenicillin side chain precursor). Phenylacetic acid is a weak acid that is toxic to cells depending on the concentration and the culture $\mathrm{pH}$. This compound can be metabolized in P. chrysogenum through at least two routes; incorporation to the benzylpenicillin molecule or catabolism via the homogentisate pathway [48-51] (Figure 2(b)). The first step of the homogentisate pathway consists of 2-hydroxylation of phenylacetic acid ring yielding 2-hydroxyphenylacetate. This reaction is catalyzed by a microsomal cytochrome P450 monooxygenase (phenylacetic acid 2-hydroxylase; phenylacetate, $\mathrm{NAD}(\mathrm{P})$ : oxygen oxidoreductase (2-hydroxylating); EC number 1.14.13), 


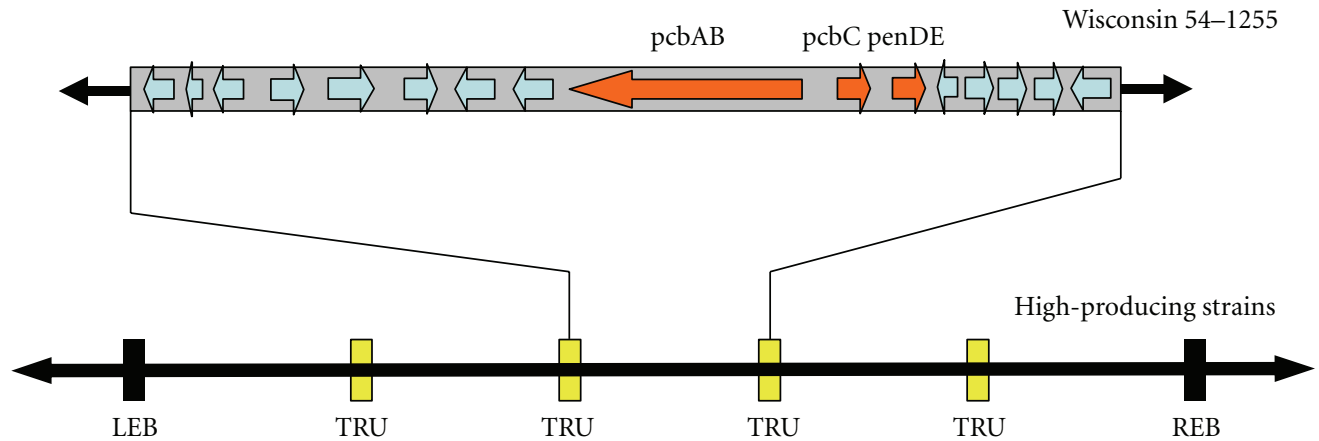

(a)

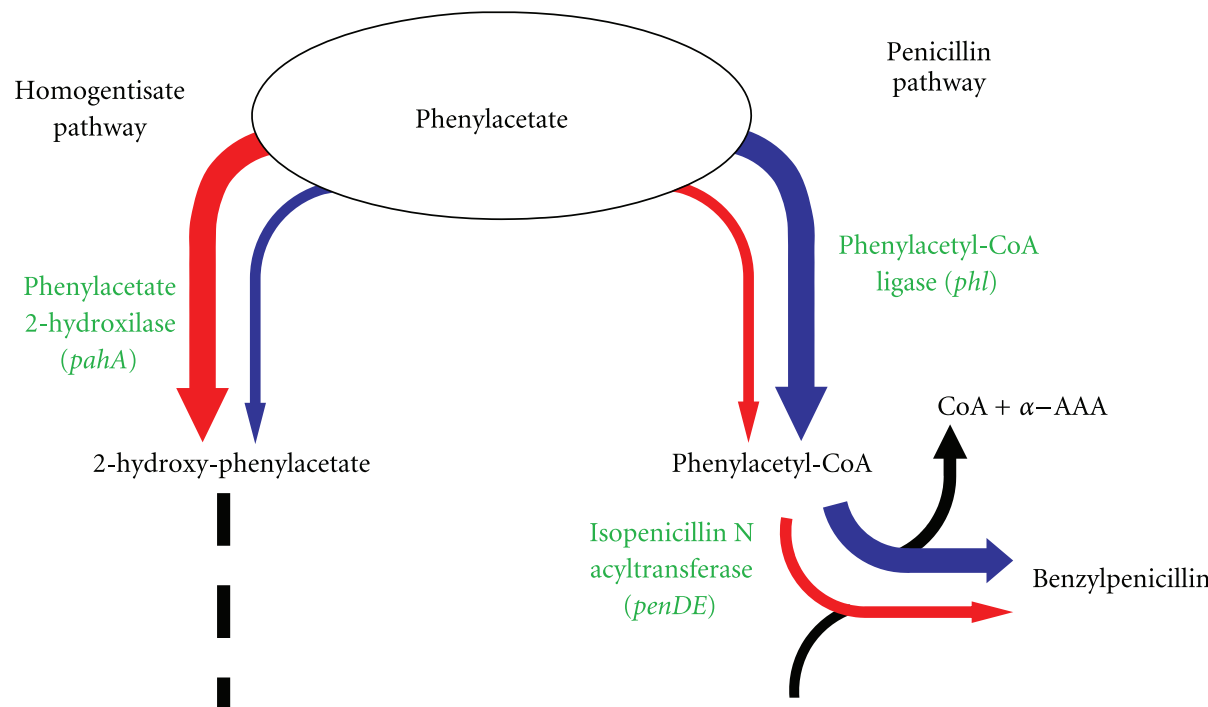

Isopenicillin $\mathrm{N}$

Fumarate + acetoacetate

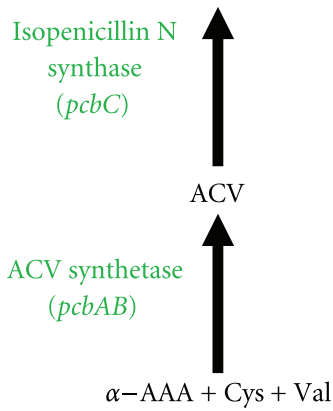

(b)

FIGURE 2: Examples of two well-known modifications that occurred during the strain improvement program. (a) Amplification of the DNA region containing the penicillin biosynthetic gene cluster in high-producing strains. LEB: left end border; REB: right end border; TRU: tandem repetition union. (b) Modification in the metabolic fluxes through the homogentisate pathway for phenylacetic acid catabolism and the penicillin biosynthetic pathway. Thickness of arrows indicates the flux rate through a specific enzyme. $\alpha$-AAA: $\alpha$-aminoadipic acid; ACV: $\delta$-(L- $\alpha$-aminoadipyl)-L-cysteinyl-D-valine; CoA: coenzyme A; Cys: cysteine; Val: Valine, Barreiro et al., 2011.

which is encoded by the pahA gene. Sequencing of the pahA gene from several strains of $P$. chrysogenum revealed that whereas the wildtype strain (NRRL 1951) contains a C at position 598 of the gene, the 49-133 strain (and likewise its descendant Wisconsin 54-1255) replaces this nucleotide with a $\mathrm{T}$ [52]. This modification in the gene sequence originates an L181F mutation in the protein, which is responsible for the reduced function of the enzyme. Therefore, the catabo- lism of phenylacetic acid through the homogentisate pathway is diminished in Wisconsin 54-1255 and, presumably, in derived strains as well, leading to a reduced degradation of phenylacetic acid and to penicillin overproduction [52] (Figure 2(b)). The importance of this enzyme in penicillin production was also highlighted after the comparative analysis of the pahA gene of P. notatum (the Fleming's isolate) and $P$. chrysogenum NRRL 1951 (the wildtype strain isolated 
in Peoria). The latter strain shows a C1357T (A394V) mutation in this gene that is conserved in Wisconsin 54-1255 (and presumably, in derived strains as well). This mutation is responsible for a loss of function in the phenylacetic acid 2hydroxylase, which is directly related to penicillin overproduction and supports the historic choice of $P$. chrysogenum as the industrial producer of penicillin [53]. Therefore, the consecutive accumulation of point mutations in the phenylacetic acid 2-hydroxylase is another reason that made P. chrysogenum a good penicillin producer.

A direct relation between microbody (peroxisome) abundance and increased penicillin titers was also observed [54]. Microbodies are organelles involved in the final steps of the penicillin pathway, which are catalyzed by the acyl-coenzyme A: isopenicillin $\mathrm{N}$ acyltransferase (IAT) and phenylacetyl-CoA ligase $[18,55,56]$. In fact, it has been reported that microbody volume fractions are enhanced in high-producing strains [57]. Compartmentalization of the penicillin pathway between cytosol and microbodies has been crucial for productivity. P. chrysogenum seems to have lost its capability to synthesize penicillins in the cytosol [58], and peroxisomes are required for efficient penicillin biosynthesis [59].

In addition to these observations, some modifications remained hidden until the arrival of the "omics" era. The publication of the genome sequence of $P$. chrysogenum Wisconsin 54-1255 [57] represented the ultimate springboard for several studies aimed to decipher the genetic secrets of the industrial production of penicillin. Some modifications that have been reported are the introduction of a $14 \mathrm{bp}$ repeat in a cephalosporin esterase homolog between Q-176 and Wisconsin 54-1255 (disturbing the ORF), which suggests a reduction in unwanted $\beta$-lactam degradation, or a mutation in an $\mathrm{ABC}$ transporter homolog between Q-176 and Wisconsin 54-1255, suggesting a change in transport capabilities [60]. Transcriptomics data revealed that expression of genes involved in biosynthesis of the amino acid precursors for penicillin biosynthesis (cysteine, valine, and $\alpha$-aminoadipic acid) was higher in the high-producing strains. The same trend was followed by several genes encoding microbody proteins [57]. Interestingly, the transcription of the penicillin biosynthesis genes $p c b A B, p c b C$, and $p e n D E$ was only twoto fourfold higher in the high-producing strain [57] suggesting that changes in other metabolic pathways related to penicillin biosynthesis have contributed as much to penicillin biosynthesis as the amplification of the three direct biosynthetic genes. Another interesting study dealing with transcriptomics was carried out by Harris and coworkers [61]. These authors analysed the expression responses of P. chrysogenum to the addition of the side-chain precursor phenylacetic acid and found that the homogentisate pathway genes, as well as those genes involved in nitrogen and sulfur metabolism, were upregulated strongly in those cultures supplemented with the side chain precursor.

Although the above-mentioned reports on genomics and transcriptomics provided a global overview of some mechanisms contributing to increased penicillin production, full exploitation of $P$. chrysogenum still required the integration of other "omics," such as proteomics. In fact, as we will show in next sections, the study of the proteome was crucial to decipher the molecular mechanisms responsible for the improved productivity of $P$. chrysogenum.

\section{Methodology of the Intracellular Protein Extraction in P. Chrysogenum}

As previously described, the vast knowledge accumulated along decades about the $P$. chrysogenum metabolism, and penicillin production contrasts with the scare information generated about methodology related with the "omics" approach, particularly with proteomics. Thus, the most basic procedures such as good-quality protein extraction for bidimensional analysis should be updated. A bibliographic search shows different procedures for protein extraction, precipitation, or protein solubilization that should be adapted for P. chrysogenum. These extraction procedures, in the case of free-living microorganisms, have some common steps, such as the mechanical breaking, the use of protease inhibitors, reducing agents, and TCA precipitation for intracellular proteomes that help in the protocol update.

The process to obtain cytoplasmic proteins should include an initial step to discard the media, unbroken mycelia, cell wall, and membrane contaminants in order to present the intracellular proteome as clean as possible. Thus, when cultures reach the desired conditions, the most common mycelia-collection process is filtration, since centrifugation of mycelial microorganisms does not generate compact pellets that make the subsequent washing steps difficult. This procedure can be done by filtering through a Whatman $3 \mathrm{MM}$ paper (Whatman, Maidstone, England) or nylon filters (Nytal Maissa, Barcelona, Spain) [62-65]. Hence, mycelia is collected and washed, and the media can be stored for further analysis of secreted proteins (Figure 3). Washing steps, which allow the media elimination that can interfere in the protein purification, are usually done at $4^{\circ} \mathrm{C}$ so as to diminish the protein lysis by intracellular proteases. The most commonly employed washing solutions are (i) water [64, 66, 67]; (ii) phosphate buffered saline (PBS) [68], or (iii) combination of $0.9 \%$ sodium chloride and water [69]. In order to prevent protein degradation, samples collected at different time points or conditions are washed, paper-dried, and immediately stored at $-20^{\circ} \mathrm{C}$ to $-80^{\circ} \mathrm{C}$ for several months.

Regarding the intracellular protein extraction, keeping the temperature as low as possible and the addition of protease inhibitors are two common steps included in all the protocols. Thus, the use of liquid nitrogen to decrease warming of the disruption systems is a widely used method. The main breaking system is the traditional prechilled mortar grinder due to its efficiency against the fungal cell wall $[68,70,71]$ although waring blender machines [62], or glass bead-beating systems, either combined with a $10 \mathrm{mM}$ Tris$\mathrm{HCl}$ buffer [72] or with a phenol buffer [64, 70], have been successfully applied. After the breaking step, the protein solubilization buffer always includes a protease inhibitor (e.g., protease inhibition cocktail for fungi and yeast (Sigma), COMPLETE (Roche) $[63,69]$, in addition to a reducing agent (e.g., 2-mercaptoethanol (BME), Dithiothreitol (DTT)) that reduces the disulfide linkages between two 


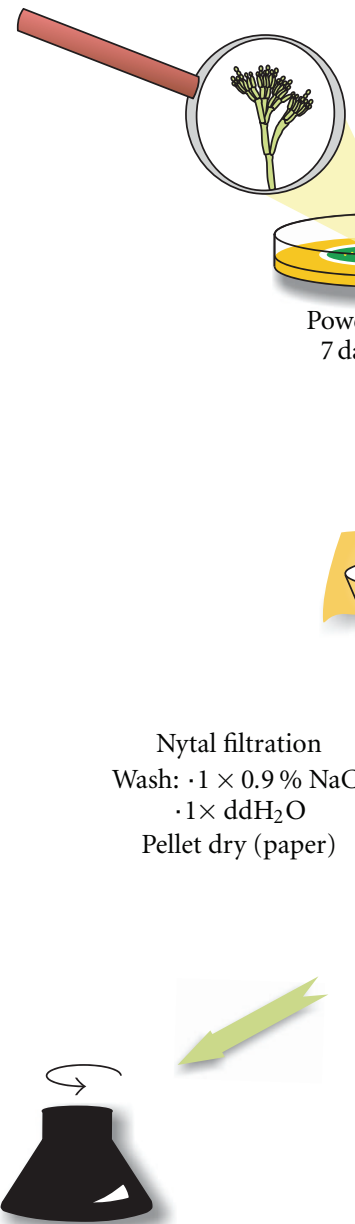

$10 \mathrm{~mL}$ tube: $3900 \times \mathrm{g}, 5 \mathrm{~min}, 4^{\circ} \mathrm{C}$ $1.5 \mathrm{~mL}$ tube: $13000 \times \mathrm{g}, 5 \mathrm{~min}, 4^{\circ} \mathrm{C}$

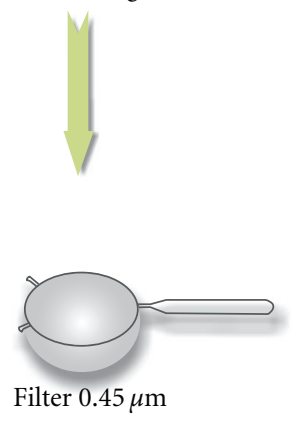

[8 M urea, $2 \%$ (w/v) CHAPS, $0.5 \%$ (v/v) IPG buffer $\mathrm{pH} 3-10$ nonlinear (NL), $20 \mathrm{mM}$ DTT, $0.002 \%$ bromphenol blue] Shake $1 \mathrm{~h}, \mathrm{R} / \mathrm{T}$. store $-20^{\circ} \mathrm{C}$

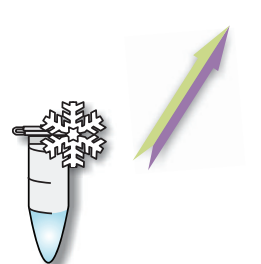

$500 \mathrm{~mL}$ nonbaffled flask 100 mL PMMY medium $250 \mathrm{rpm}$ (defined)
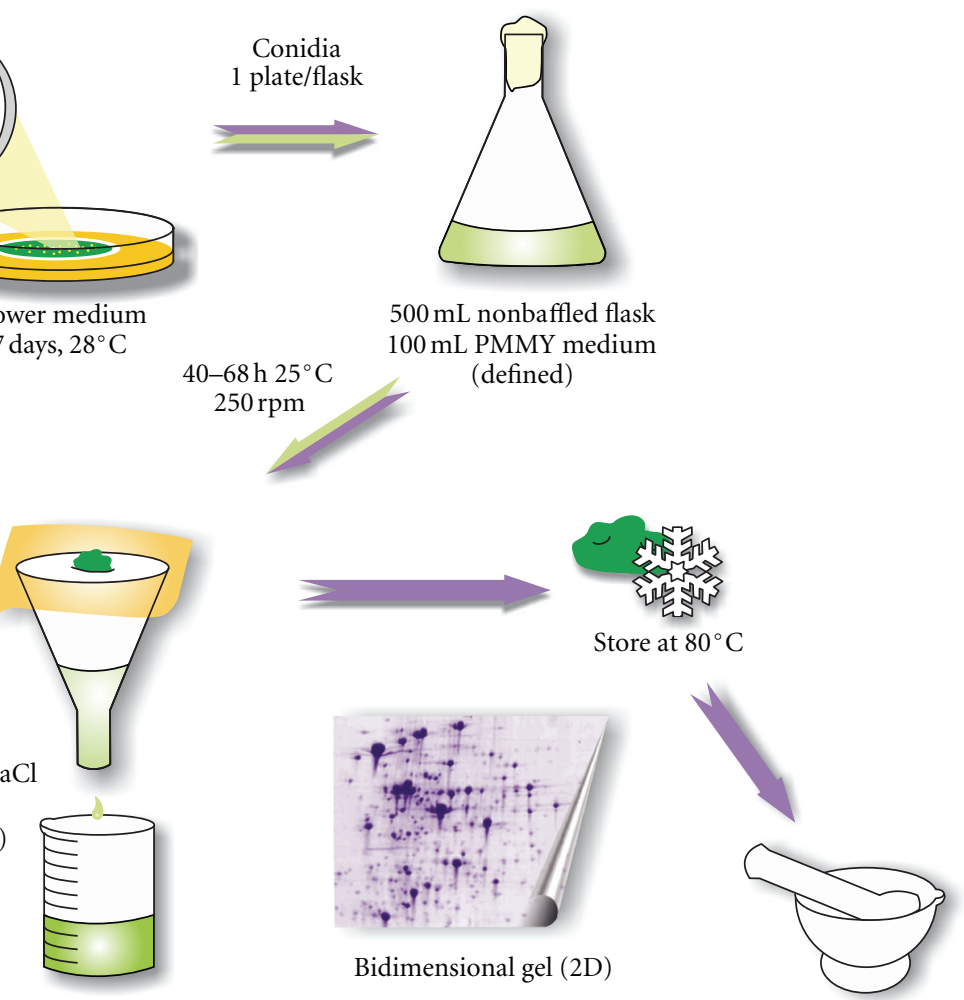

Precooled mortar (liquid $\mathrm{N}_{2}$ ) Fine powder
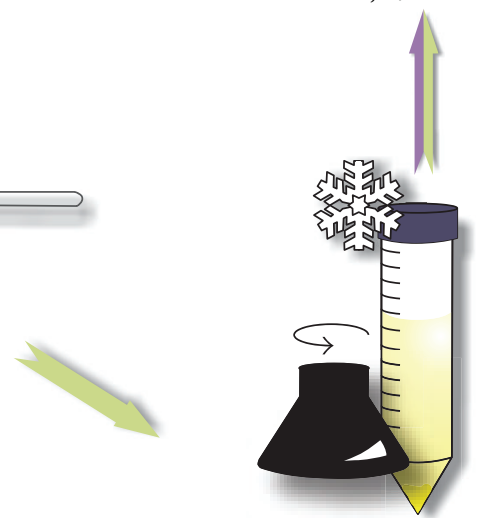

$20 \%$ TCA + 0.14\% DTT (vol:vol). $1 \mathrm{~h},-20^{\circ} \mathrm{C}$ wash: $\cdot 2 \times$ acetone $-20^{\circ} \mathrm{C}$ $\cdot 1 \times 80 \%$ acetone

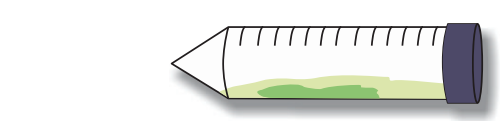

$2 \mathrm{~g}$ mycelia/10 $\mathrm{mL}$ buffer (ratio $1: 5$ ) $\left[10 \mathrm{mM}\left(\mathrm{K}_{2} \mathrm{HPO}_{4}: \mathrm{KH}_{2} \mathrm{PO}_{4}\right) ; 0.07 \%\right.$ DTT; pH 7.4]. 1 tablet complete/ $10 \mathrm{~mL}$ buffer Shake $2 \mathrm{~h}, 4^{\circ} \mathrm{C}$
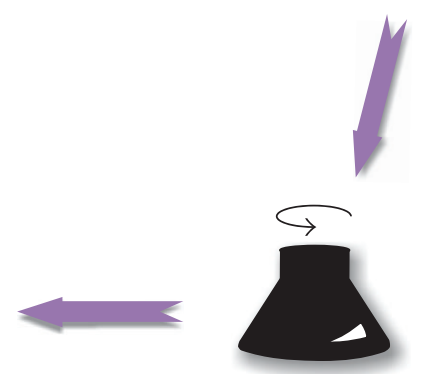

Clarify: $13000 \times \mathrm{g}, 5 \mathrm{~min}, 4^{\circ} \mathrm{C}$

FIGURE 3: Schematic representation of the optimized method for mycelia and secreted proteins collection of P. chrysogenum in order to analyze the intracellular and extracellular proteomes. Green/purple-coloured arrows show the common steps for both methods. Green arrows represent the specific method for secreted proteins isolation. Purple arrows show those steps specific for intracellular proteome isolation, Barreiro et al., 2011. 
cysteines $[63,66]$. Frequently, the reducing agent is added to the precipitation solution (0.093\% BME, $0.14 \%$ DTT). This precipitation step (previous to resuspension in sample solution) is employed to selectively purify proteins from contaminants such as salts, nucleic acids, detergents, or lipids, which interfere the final bidimensional analysis. Although the combination of trichloroacetic acid (TCA) and acetone is usually more effective than either TCA or acetone alone [73], other mixtures, such as methanol/ammonium acetate, have been described for fungi [70]. Optionally, a nuclease mix $\quad\left(0.5 \mathrm{mg} \mathrm{mL}^{-1}\right.$ DNase, $0.25 \mathrm{mg} \mathrm{mL}^{-1}$ RNase, and $50 \mathrm{mmol} \mathrm{L}^{-1} \mathrm{MgCl}_{2}$; or commercially available, for example, Benzonase (Merck)) can be used as additional treatment before sample precipitation $[68,74]$. When the precipitation step is omitted, direct solubilization in homogenization buffer is done, which includes fungal DNase/RNase as described by $\mathrm{Oh}$ and coworkers [72].

Proteins may be difficult to resolubilize and may not resolubilize completely after TCA precipitation ("2-D Electrophoresis. Principles and Methods"; GE Healthcare). Thus, residual TCA must be removed intensively by cold acetone washing steps, for example, (i) $2 \mathrm{x}$ acetone plus $0.07 \%$ DTT and $1 \times 80 \%$ acetone [69]; (ii) $2 \mathrm{x}$ acetone containing $1 \% \mathrm{BME}$ [66, 67]; (iii) $3 \mathrm{x}$ acetone $/ 0.3 \%$ DTT (wt/vol) [70]. A helpful tip after TCA precipitation and washing is to avoid long drying periods of time in order to improve protein resuspension (1-2 minutes is enough). The main components of the final sample buffer or homogenization buffer described in fungal bibliography have urea (7-9 M), thiourea (0-2 M), CHAPS $(1-4 \% \mathrm{w} / \mathrm{v})$, and ampholyte $(0,5-2 \%)$ combined as follows:

(i) $8 \mathrm{M}$ urea, $2 \mathrm{M}$ thiourea, $1 \%(\mathrm{w} / \mathrm{v})$ CHAPS, $20 \mathrm{~mm}$ DTT, and 0,5\% (v/v) ampholyte 3-10 [65];

(ii) $8 \mathrm{M}$ urea, 2\% CHAPS, $20 \mathrm{mM}$ DTT, and $0.5 \%(\mathrm{v} / \mathrm{v})$ biolytes [63];

(iii) $7 \mathrm{M}$ urea, $2 \mathrm{M}$ thiourea, $4 \%$ CHAPS $(\mathrm{w} / \mathrm{v}), 20 \mathrm{mM}$ DTT, and 1.0\% IPG buffer (v/v) [67];

(iv) $7 \mathrm{M}$ urea, $2 \mathrm{M}$ thiourea, $4 \%(\mathrm{w} / \mathrm{v})$ CHAPS, $0.8 \%(\mathrm{v} / \mathrm{v})$ ampholytes, $20 \mathrm{mM}$ Tris, and $20 \mathrm{mM}$ DTT [66];

(v) $7 \mathrm{M}$ urea, $2 \mathrm{M}$ thiourea, 2\% (w/v) CHAPS, $1 \%(\mathrm{w} / \mathrm{v})$ Zwittergent 3-10, and $20 \mathrm{mM}$ Tris [70];

(vi) $7 \mathrm{M}$ urea, $2 \mathrm{M}$ thiourea, $4 \%(\mathrm{w} / \mathrm{v})$ CHAPS, $1 \%(\mathrm{w} / \mathrm{v})$ DTT, $20 \mathrm{mM}$ Tris, and 1\% (v/v) Pharmalyte $\mathrm{pH} 3-10$ [68];

(vii) $8 \mathrm{M}$ urea, $4 \%$ CHAPS, $40 \mathrm{mM}$ Tris-pH 7.4, $100 \mathrm{mM}$ DTT, and $0.2 \%$ ampholyte [72].

A protocol described by Kniemeyer and coworkers [66] for protein extraction of Aspergillus fumigatus summarized part of the steps described above, since after the mycelia homogenization in a pre-cooled (in liquid nitrogen) mortar they did the extraction, cleaning, and precipitation steps together, using the Clean-Up kit (GE Healthcare). This procedure produced quite good results when it was applied to P. chrysogenum (Figure 4(a)) showing a good protein yield. However, some problems, such as the poor representation of large proteins $(>75 \mathrm{kDa})$, stripping in the basic region, and the improper cleaning of the middle-sized protein region (50-100 kDa), were observed. Notwithstanding the fact that some problems are described, this procedure can be applied for fungal protein extraction.

Based on the methods described by Fernández-Acero and coworkers [63] for Botrytis cynera, the mortar grinding approach combined with a phosphate buffer extraction was used for $P$. chrysogenum. This method improved the final bidimensional gel results (Figure 4(b)), replacing the lacks observed in the direct Clean-Up kit method. In addition, this procedure yielded large protein amounts, which allowed blue silver Coomassie colloidal staining [76], thus simplifying the $2 \mathrm{D}$ gels handling.

As a conclusion of the protocols and the experimental work found in literature, the best protein extraction method for P. chrysogenum (Figure 3) was the one described in our laboratory by Jami and coworkers [69], which consisted of the following.

(i) Filtrate through nylon filters (Nytal membrane), $1 \mathrm{x}$ $0.9 \% \mathrm{NaCl}$ washing, $2 \mathrm{x} \mathrm{ddH} 2 \mathrm{O}$ washing, paper dried and stored at $-80^{\circ} \mathrm{C}$.

(ii) Grinding of two grams of mycelia to a fine powder in a pre-cooled mortar using liquid nitrogen.

(iii) Stirring the homogenized powder at $4^{\circ} \mathrm{C}$ for $2 \mathrm{~h}$ in $10 \mathrm{~mL}$ (ratio: $1 \mathrm{~g} / 5 \mathrm{~mL}$ ) of phosphate buffer $(10 \mathrm{mM}$ potassium phosphate buffer $\left(\mathrm{K}_{2} \mathrm{HPO}_{4}: \mathrm{KH}_{2} \mathrm{PO}_{4}\right)$ ( $\mathrm{pH}$ 7.4) containing $0.07 \%(\mathrm{w} / \mathrm{v})$ DTT and supplemented with tablets of protease inhibitor mixture complete (one tablet $/ 10 \mathrm{~mL}$ of buffer)). Clarify by centrifugation at $13000 \times \mathrm{g}$ for $5 \mathrm{~min}$ twice.

(iv) Protein precipitation for $1 \mathrm{~h}$ at $-20^{\circ} \mathrm{C}$ after addition of 1 volume of $20 \%$ TCA in acetone containing $0.14 \%$ $(\mathrm{w} / \mathrm{v})$ DTT. Harvest the protein pellet at $4,000 \times \mathrm{g}$, 5 minutes at $4^{\circ} \mathrm{C}$. Washing steps: $2 \mathrm{x}$ acetone and $1 \mathrm{x}$ $80 \%$ acetone (salt elimination). Solubilization of the final pellet was done by shaking $1 \mathrm{~h}$ at room temperature in $500 \mu \mathrm{L}$ of sample buffer ( $8 \mathrm{M}$ urea; $2 \%(\mathrm{w} / \mathrm{v})$ CHAPS; 0.5\% (v/v); IPG buffer pH 3-10 nonlinear (NL) (GE Healthcare); $20 \mathrm{mM}$ DTT; $0.002 \%$ bromophenol blue).

(v) Centrifugation at 13,200 rpm for 1 min to discard the insoluble fraction. The supernatant was collected, and protein concentration was determined according to the Bradford method [77].

As a result of the protein extraction method optimization, an interactive reference map suitable for protein location of $P$. chrysogenum Wisconsin 54-1255 (reference strain) was uploaded at the website: http://isa.uniovi.es/ P_chrysogenum_proteome/.

\section{Industrial Strain Evolution of P. chrysogenum from the Proteomics Point of View}

The evolution of the penicillin producer strains, as previously described (Section 2), has been a complex process of random 


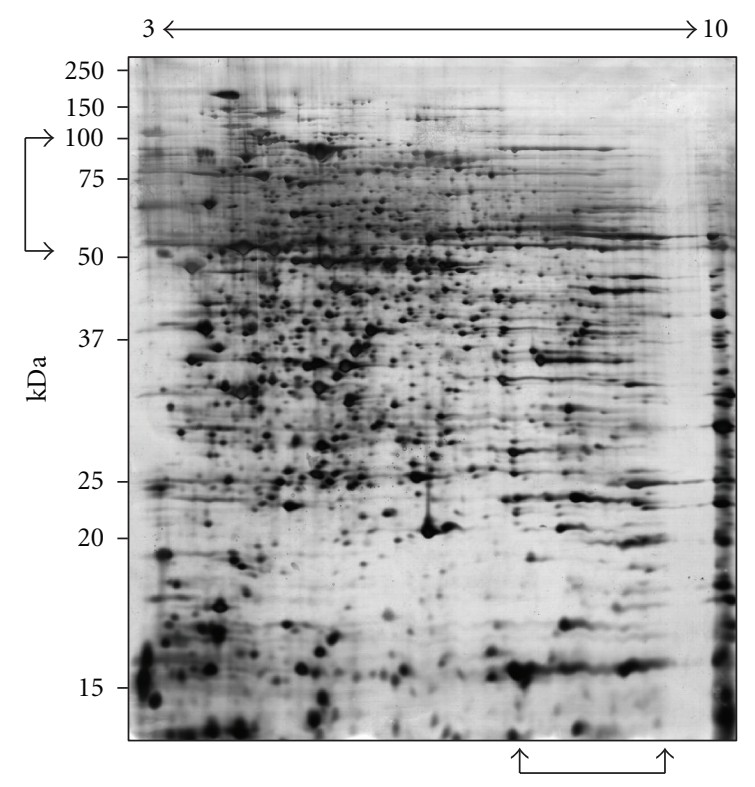

(a)

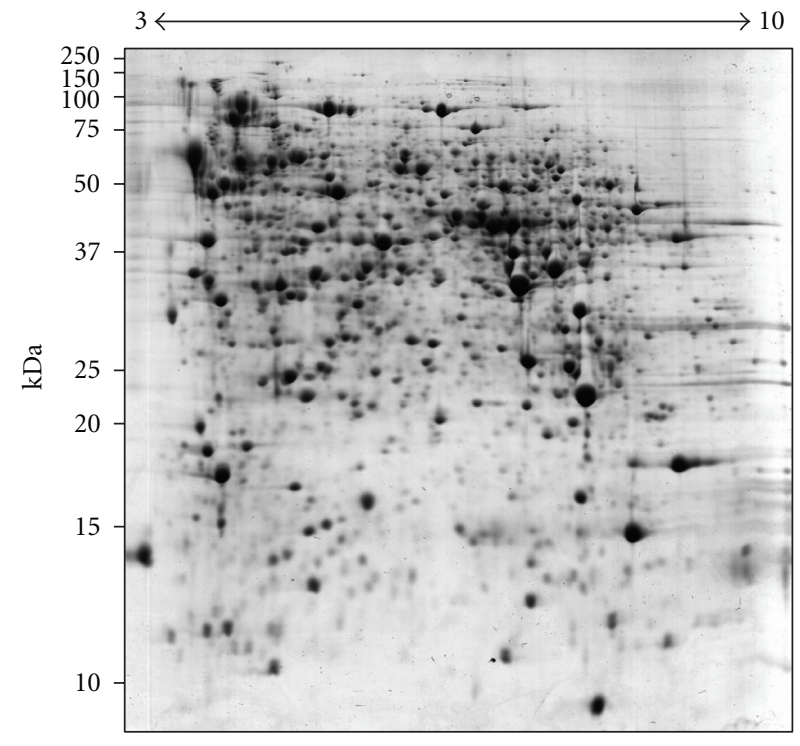

(b)

FIgURE 4: Optimization of the protein extraction protocol from mycelia of P. chrysogenum. (a) Extraction and purification of protein samples with "Clean-Up Kit" (GE Healthcare), based on Kniemeyer and coworkers [66] and silver stained. As sample buffer was used, $7 \mathrm{M}$ urea, $2 \mathrm{M}$ thiourea, 4\% (w/v) CHAPS, 0.8\% (v/v) IPG buffer pH 3-10 nonlinear (NL) (GE Healthcare), $40 \mathrm{mM}$ Tris, 1 mM EDTA, and 20 mM DTT [75]. (b) The extraction is based on the method described by Fernández-Acero and coworkers [63] by using mortar gridding and phosphate buffer, plus blue silver Coomassie colloidal staining [76]. As sample buffer was used, $8 \mathrm{M}$ urea, 2\% (w/v) CHAPS, 0.5\% (v/v) IPG buffer pH 3-10 NL (GE Healthcare), $20 \mathrm{mM}$ DTT, and 0.002\% bromophenol blue [69]. Precision plus protein standards (Bio-Rad) were used as markers. The molecular mass is indicated in kilo-Daltons $(\mathrm{kDa})$. Note the problematic regions observed with the extraction method A, which are highlighted by arrowed square brackets (left and bottom), Barreiro et al., 2011.

mutagenesis and further screening. This system accumulates beneficial unknown mutations, which increased the final titers of penicillin, but does not provide clues about the modified genes or proteins. The recent application of proteomic techniques has allowed the identification of several of these modifications, which opens the option for the genome breeding approach to fungi following the steps developed in other microorganisms [78]. Along the strain improvement process, several metabolic pathways have been redirected to obtain (i) more precursors, (ii) energy-supplying molecules for the penicillin synthesis in parallel to (iii) decrease in virulence or pigment production (Figure 5). Comparison among three different strains of $P$. chrysogenum: (i) NRRL 1951 (wildtype strain), (ii) Wisconsin 54-1255 (model strain; moderate production), and (iii) AS-P-78 (high-producing strain) showed a clear picture of the industrial improvements [69] (Figure 1). Thus, the three precursor amino acids (L- $\alpha$-aminoadipic acid, L-cysteine and L-valine) involved in the nonribosomal condensation, which is the initial step of penicillin synthesis, presented a decrease of their catabolic pathways: (i) cysteine catabolism (cystathionine $\beta$-synthase); (ii) valine catabolism (methylmalonate-semialdehyde dehydrogenase); (iii) fatty acid degradation (phytanoyl-CoA dioxygenase family protein) and an increase of their biosynthetic pathways involved in the penicillin synthesis: (i) cysteine synthesis (cysteine synthase), (ii) valine synthesis (branched-chain amino acid aminotransferase), and (iii) branched amino-acid synthesis (dihydroxy-acid dehydratase). Surprisingly, the high-producer strain (AS-P78) does not present a significant overrepresentation of the proteins directly involved in the penicillin production, despite the fact that AS-P-78 contains five or six copies of the amplified region that includes the penicillin biosynthetic genes $[34,38]$ (see Section 2). Similar results were obtained with transcriptomic analysis using other high-producing strains [57]. In fact, the lack of a linear relationship between the number of copies of the penicillin gene cluster and the penicillin titers was previously observed [36]. In summary, it was concluded that penicillin gene cluster amplification is not the main mechanism that transformed the wildtype strain (NRRL 1951) into a penicillin overproducer (AS-P78 ), even when it had a clear impact on production.

The penicillin titers are also increased in high-producing strains by the downregulation of penicillin modification or degradation-related proteins, such as an esterase, which contains a $\beta$-lactamase domain possibly involved in penicillin degradation. Besides, there are proteins involved in other secondary metabolite production pathways underrepresented in the high-producing strain, which decreased their expression throughout industrial strain evolution. A 3-hydroxy3-methylglutaryl-CoA synthase and a coproporphyrinogen oxidase III involved in terpenoid synthesis and porphyrin metabolism, respectively, are clear examples of this redirection of metabolism [69].

The wildtype strain (NRRL 1951) presents a variety of proteins involved in pigment formation, in agreement with 


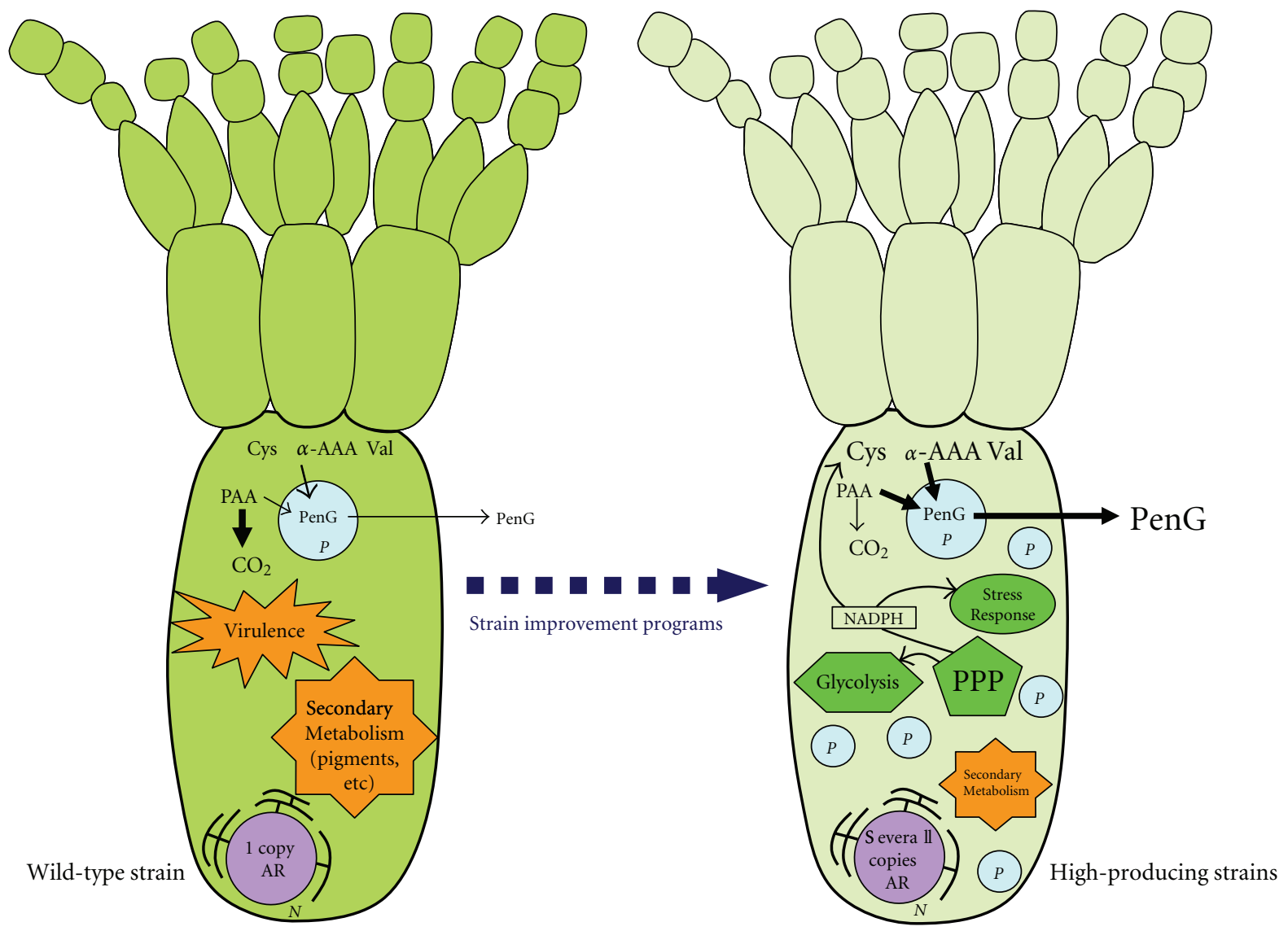

FIGURE 5: Pathways and networks modified during the strain improvement program. Font size is in concordance with concentration and differences; the thickness of arrows indicates the flux through a specific pathway. $\alpha$-AAA: $\alpha$-aminoadipic acid; Cys: cysteine; N: nucleus; NADPH: reduced form of nicotinamide adenine dinucleotide phosphate; P: peroxisome; PAA: phenylacetic acid; PenG: benzylpenicillin; PPP: pentose phosphate pathway; Val: valine, Barreiro et al., 2011.

the well-known ability of this strain to synthesize large amounts of pigment, which decreased or disappeared in the industrial strains. Thus, a zeaxanthin epoxidase involved in natural xanthophyll pigment production is 11-fold downrepresented in the AS-P-78 strain, and a scytalone dehydratase (involved in the biosynthesis of melanin protecting hyphae and spores from UV light, free radicals, and desiccation in addition to serving as a virulence factor [79]) is only present in the wildtype strain. As it was mentioned above, during the mutagenic treatments (from Q-176 to BL3-D10 strains), pigmentless strains were selected (Figure 1).

The analysis of the cytoplasmatic proteome has also shown a rearrangement of the internal energetic fluxes through the glycolysis and pentose phosphate pathways to the penicillin biosynthetic pathway, which constitutes a major burden on the supply of NADPH. In the one hand, the AS-P-78 (high production) strain overproduces enzymes of the pentose phosphate pathway like ribose-5-phosphate isomerase or transketolase [69]. It is likely that a high concentration of ribulose 5-phosphate, together with reducing power in the form of NADPH, is formed in the high-producer strain. Thus, this sugar phosphate excess is converted by the ribose-5-phosphate isomerase into ribulose 5-phosphate (precursor of nucleic acids and nucleotides) and glycolysis precursors by the transketolase, which connects both metabolic pathways (pentose phosphate and glycolysis) [69]. On the other hand, the NADPH level is strongly correlated to $\beta$-lactam production $(8-10 \mathrm{~mol}$ of NADPH are required for the biosynthesis of $1 \mathrm{~mol}$ of penicillin) [80]. In addition, the ATP level and cysteine concentration have been reported to have a great influence over the penicillin production [81]. Because NADPH is required for cysteine biosynthesis, a positive relationship among cysteine, NADPH levels, and penicillin production can be established [81]. In addition, the increase in cysteine biosynthesis could be also related to an increased demand for glutathione biosynthesis to cope with higher levels of the oxidative stress related to high aeration rates in the high penicillin producer strain. Besides, the oxidized glutathione during oxidative stress requires NADPH to reduce it. Therefore, the connection between NADPH, oxidative stress, and pentose phosphate pathway has been well established by means of the proteomics approach in $P$. chrysogenum [69] (Figure 5).

In concordance with the underrepresentation of the proteins involved in pigment formation, as well as other secondary metabolites in the high-producer strains (less energy consumption), the proteins involved in virulence are also underrepresented. This situation has been observed with 
a glucose oxidase, which has been described as involved in the pathogenicity of Penicillium expansum in apples [82] and with a host infection protein (Cap20), which plays a significant role in the fungal virulence on avocado and tomato fruits [83]. Besides, UDP-galactopyranose mutase involved in galactofuranose biosynthesis, which plays a crucial role in cell envelope formation and the infectious cycle [84], is downrepresented in the high-producer strain AS-P-78. Therefore, the decrease of proteins involved in virulence and plant cell wall degradation through the strain evolution is substantiated by the specialization on industrial raw material consumption by the mutagenized strains.

In summary, the proteomics approach through the intracellular proteome analysis has added more relevant information about the events that led to create "domesticated" strains, which are the current high penicillin producer strains.

\section{How to Guarantee the Secretome Quality?}

Even when the analysis of the extracellular proteome does not suggest a clear relation with the antibiotics production in $P$. chrysogenum, it can offer new clues either for the general understanding of the fungal metabolism or for possible industrial applications of the secreted proteins. This is the case of other secreted fungal proteins as those of Aspergillus oryzae or Aspergillus niger, which are involved in the production of fermented foods and beverages or used for the production of organic acids, food ingredients, and industrial enzymes, respectively $[85,86]$. In addition, white rot fungi (the degradation of hemicelluloses and lignin by basidiomycetes and ascomycetes) and brown rot fungi (the attack of cellulose and hemicelluloses, exclusively, accomplished by basidiomycetous) are involved in the degradation of lignocelluloses, which represent the world's largest renewable carbon source [87]. This huge biomass coming from plant primary metabolism, which is about 140 billion tons annually [88], is proposed as a possible substitute of the limited availability of fossil fuels and can be utilized easily and bioconverted with the help of fungal white biotechnology.

The most crucial step for the secreted protein analysis is to distinguish the proteins really secreted from those contaminant proteins coming from cell lysis events. This capital process can be tackled sequentially from three different points of view: (i) sample collection; (ii) post-identification protein analysis; (iii) "moonlighting proteins" and unconventional secreted protein analysis.

Some tips in the collection of secreted protein are shown in Figure 3, such as the intensive mycelia elimination process (the use of nylon filters, rigorous centrifugation, and filtration through $0.45 \mu \mathrm{m}$ filters) or the use of low temperatures to avoid mycelia degradation. Sample collection is also crucial to discard those non-natural secreted proteins. It is described in the scientific literature how the presence of extracellular proteins in the culture medium is correlated directly to the growth phase [89]. Jami and coworkers [90] showed the linear correlation existing between the presence of proteins in the culture medium and the culture growth (biomass formation). Interestingly, the increase in the amount of proteins that were present in the culture medium continued even after the culture reached the stationary phase. One explanation is that some of those proteins were present in the culture medium as a result of cell lysis events. Consequently, the sample uptake should be done at an early time point, but coincident with a moment of optimal extracellular protein secretion. For example, $P$. chrysogenum does not show significant amounts of secreted proteins before 24 hours [90].

Related to the post-identification protein analysis, the comparison between secreted proteins at $68 \mathrm{~h}$ versus those secreted at $40 \mathrm{~h}$ in $P$. chrysogenum was done as an additional control [90]. It was seen that the expression differences observed during the time course were mainly due to the presence at $40 \mathrm{~h}$ of isoforms from lately expressed proteins and to proteins expressed only at late stages. As a conclusion, the amount of possible contaminant intracellular proteins in the secretome was reported to be very low (6.09\%) in P. chrysogenum [90]. When the intracellular proteome is known, the presence of contaminant proteins due to cell lysis can be tested by the presence of intracellular high-abundance proteins. Thus, malate dehydrogenase and glyceraldehydes3-phosphate dehydrogenase in Botrytis cinerea or the flavohemoglobin and manganese superoxide dismutase in P. chrysogenum should be detected in the case of lysis events, since these are the most abundant intracellular proteins [69, 91]. However, sometimes it is difficult to ascertain whether a protein is secreted truly or is present in the culture medium as a consequence of cell lysis. Recently, new bioinformatics tools have been developed to characterize the secreted proteins either in a classical or non-classical way by means of prediction of secretion signal motifs. SignalP (for classical secretion signal motifs) and SecretomeP (for nonclassical signal motifs) are useful prediction softwares [92, 93] that can be used for such purpose. The availability of several fungal genomes in databases together with the use of those prediction programs for secretory proteins has allowed the recent development of platforms for the annotation of fungal secretomes, such as the Fungal Secretome Database [94] or the Fungal Secretome KnowledgeBase (FunSecKB [95]), which allow the proper identification of secreted proteins.

Even when the above-mentioned information is taken into account and you have the certainty of working with secreted proteins, some unconventional proteins, dubbed "moonlighting proteins" [96], can be detected. These proteins present unconventional protein secretion systems [9799], and then, it is difficult to define their authenticity as secreted proteins. One meaning of moonlighting, according to The Compact Oxford English Dictionary [100], is "to do paid work, usually at night, in addition to one's regular employment"; therefore, "moonlighting proteins" is a quite appropriate designation for the collective of multifunctional proteins, which are widespread among organisms ranging from bacteria to mammals [101]. In spite of this ubiquity, more attention has been traditionally given to the "moonlighting proteins" found in higher eukaryotes, but recently the yeasts have caught the attention for lower eukaryotes $[101,102]$. Thus, in many cases, the fusion of two genes that initially encoded proteins with single functions has been 
the origin of that duality. On the other hand, a significant number of proteins can perform dissimilar functions [101, 102].

Another phenomenon that has been observed in the P. chrysogenum secretome is the fact that some extracellular proteins identified in the reference map were also identified previously by Kiel and coworkers [103] in the microbody matrix of this fungus. Therefore, an alternative explanation given to the presence of intracellular proteins in the culture broth was the selective autophagic degradation of peroxisomes (pexophagy), which can give a new sense to the strange "moonlighting proteins" as we explained in P. chrysogenum [90]. It is well known that peroxisome abundance can be decreased rapidly through autophagic pathways, which selectively degrade peroxisomes by fusion to lysosomes or vacuoles [104]. Integration of peroxisomes into vacuoles may lead to secretion of the proteins located in the peroxisomal matrix by exocytosis, a mechanism that has been discussed as an alternative route for the release of penicillin from peroxisomes to the culture medium [18].

Taking into account all these factors, the analysis of the extracellular proteome of $P$. chrysogenum has been completed fully [90]. It can be consulted in an interactive way by means of the reference map present at the website: http://isa. uniovi.es/P_chrysogenum_secretome/.

\section{Penicillium chrysogenum: A Versatile Cell Factory for Biotechnology}

Genome sequence of $P$. chrysogenum revealed the presence of several nonribosomal peptide synthetases (NRPSs), polyketide synthases (PKSs), and hybrid NRPS-PKS enzymes [57], highlighting the potential of this microorganism to produce other secondary metabolites different from penicillin. Even more interesting than the production of homologous secondary metabolites is the potential use of $P$. chrysogenum as a host for the biosynthesis of heterologous secondary metabolites. In fact, due to the good metabolic fluxes of the penicillin biosynthetic pathway, P. chrysogenum was engineered to produce cephalosporin intermediates [105-107]. The available information about fermentation conditions and optimization of $P$. chrysogenum to industrial conditions has promoted the development of host strains that lack the penicillin gene cluster $[61,108]$, which could be optimal for the production of heterologous metabolites.

In addition to secondary metabolites, secreted enzymes also reflect the versatility of $P$. chrysogenum. The analysis of the secretome of this fungus [90] has also suggested the potential interest of nonpenicillin producer strains for other biotechnological uses, such as food and beverage industries. Some proteins identified in the culture medium of P. chrysogenum are of interest for this biotechnological area. This is the case of a probable isoamyl alcohol oxidase, an extracellular enzyme in A. oryzae catalyzing the formation of isovaleraldehyde, which is the main component of mureka that gives sake an off-flavor [109]. Another example is sulphydryl oxidase, which may be used for treatment of bakery products or for removal of off-flavour from UHT-treated milk or beer [110]. A relevant enzyme for its application in food industry is dihydroxy-acid dehydratase, which removes vicinal diketones. These compounds are responsible for the off-flavor of diacetyl (butter flavor or sweaty flavor in beer, "tsuwari-ka," or nauseating flavor in sake) in brewed alcoholic beverages. Overproduction of dihydroxy-acid dehydratase in S. cerevisiae has been patented to produce alcoholic beverages with superior flavor [111]. It is also important the secretion of a prolyl aminopeptidase during the ripening of the Camembert cheese since it decreases the amount of bitter tasting peptides [112]. Other proteins, such as pectinolytic enzymes, which play an important role in beverage and juice industries, were also found in the secretome of $P$. chrysogenum. Additional relevant secreted enzymes are ferulic acid esterases, which release ferulic acid (a naturally occurring hydroxycinnamic acid derivative with beneficial medical effects [113]) from plant cell walls. It has been proposed that ferulic acid esterases have the ability not only to degrade plant biomasses, but also to synthesize novel bioactive components [114].

Although there are other systems for the production of useful proteins, such as bacteria, insects, mammalian cell culture, transgenic animal, plant cell cultures, and transgenic plants, the versatility of $P$. chrysogenum, its plasticity, its ability to grow on different media and conditions, and the availability of several mutants and tools for its genetic manipulation may confer some advantages on $P$. chrysogenum over other systems to produce and secrete high amounts of homologous and heterologous proteins.

\section{Concluding Remarks}

The new "omics" era has allowed scientists, 80 years after the Fleming's fortuitous discovery of the penicillin-producing fungus Penicillium notatum, to start to comprehend the molecular basis of the effect of six decades of classical strain improvement. Besides, the advances in microbiology, biochemistry, genetics, and molecular biology have contributed to the knowledge of structural, ancillary, and regulatory biosynthetic genes and enzymes, together with the characterization of the subcellular compartments involved in the biosynthesis of $\beta$-lactam antibiotics. Therefore, genomics, transcriptomics, proteomics, metabolomics, and fluxomics studies have revealed that major modifications in primary and secondary metabolism (phenylacetic acid catabolism, peroxisome biogenesis, pentose phosphate pathway, redox metabolism, biosynthesis of precursor amino acids, penicillin biosynthetic enzymes, etc.) occurred during the improvement programs, rebalancing several cellular processes that led to the impressive penicillin production reached by the current industrial strains. As conclusion, these findings will help the scientific community from industry and academia not only to continue the exploitation of the successful synergy existing between $P$. chrysogenum and $\beta$-lactam antibiotic production, but also to explore the production of other compounds using this versatile fungus as a cell factory. 


\section{Acknowledgments}

This work was supported partially by Grants from the European Union (Eurofung Grant QLRT-1999-00729 and Eurofungbase). C. Barreiro was supported by the European Union program ERA-IB (BioProChemBB project (EIB.08.008)). The authors acknowledge the technical assistance of the INBIOTEC staff: B. Martín, J. Merino, A. Casenave, and A. Mulero.

\section{References}

[1] J. Guarro, J. Gené, and A. M. Stchigel, "Developments in fungal taxonomy," Clinical Microbiology Reviews, vol. 12, no. 3, pp. 454-500, 1999.

[2] D. L. Hawksworth, "The fungal dimension of biodiversity: magnitude, significance, and conservation," Mycological Research, vol. 95, pp. 641-655, 1991.

[3] D. L. Hawksworth and A. Y. Rossman, "Where are all the undescribed fungi?" Phytopathology, vol. 87, no. 9, pp. 888-891, 1997.

[4] D. L. Hawksworth, "The magnitude of fungal diversity: the 1.5 million species estimate revisited," Mycological Research, vol. 105, no. 12, pp. 1422-1432, 2001.

[5] H. E. O’Brien, J. L. Parrent, J. A. Jackson, J. M. Moncalvo, and R. Vilgalys, "Fungal community analysis by large-scale sequencing of environmental samples," Applied and Environmental Microbiology, vol. 71, no. 9, pp. 5544-5550, 2005.

[6] D. S. Hibbett, A. Ohman, and P. M. Kirk, "Fungal ecology catches fire," New Phytologist, vol. 184, no. 2, pp. 279-282, 2009.

[7] M. L. Berbee and J. W. Taylor, "Ascomycete relationships: dating the origin of asexual lineages with $18 \mathrm{~S}$ ribosomal RNA gene sequence data," in The Fungal Holomorph: Mitotic, Meiotic and Pleomorphic Speciation in Fungal Systematics, D. R. Reynolds and J. W. Taylor, Eds., pp. 67-78, CAB International, Wallingford, UK, 1993.

[8] K. Voigt and P. M. Kirk, "Recent developments in the taxonomic affiliation and phylogenetic positioning of fungi: impact in applied microbiology and environmental biotechnology," Applied Microbiology and Biotechnology, vol. 90, no. 1, pp. 41-57, 2011.

[9] D. S. Hibbett, M. Binder, J. F. Bischoff et al., "A higher-level phylogenetic classification of the Fungi," Mycological Research, vol. 111, no. 5, pp. 509-547, 2007.

[10] A. Schüßler, D. Schwarzott, and C. Walker, "A new fungal phylum, the Glomeromycota: phylogeny and evolution," Mycological Research, vol. 105, no. 12, pp. 1413-1421, 2001.

[11] J. M. Palmer and N. P. Keller, "Secondary metabolism in fungi: does chromosomal location matter?" Current Opinion in Microbiology, vol. 13, no. 4, pp. 431-436, 2010.

[12] C. Olano, F. Lombo, C. Mendez, and J. A. Salas, "Improving production of bioactive secondary metabolites in actinomycetes by metabolic engineering," Metabolic Engineering, vol. 10, no. 5, pp. 281-292, 2008.

[13] A. Fleming, "On the antibacterial action of cultures of a penicillium, with special reference to their use in the isolation of B. influenzae," British Journal of Experimental Pathology, vol. 10, pp. 226-236, 1929.

[14] P. W. Clutterbuck, R. Lovell, and H. Raistrick, "Studies in the biochemistry of micro-organisms. The formation from glucose by members of the Penicillium chrysogenum series of a pigment, an alkali-soluble protein and penicillin-the antibacterial substance of Fleming," Biochemical Journal, vol. 26, no. 6, pp. 1907-1918, 1932.

[15] H. W. Florey, E. B. Chain, N. G. Heatley et al., Antibiotics, vol. 2, Oxford University Press, London, UK, 1949.

[16] K. F. Kong, L. Schneper, and K. Mathee, "Beta-lactam antibiotics: from antibiosis to resistance and bacteriology," Acta Pathologica, Microbiologica et Immunologica Scandinavica, vol. 118, no. 1, pp. 1-36, 2010.

[17] A. A. Brakhage, M. Thön, P. Spröte et al., "Aspects on evolution of fungal $\beta$-lactam biosynthesis gene clusters and recruitment of trans-acting factors," Phytochemistry, vol. 70, no. 15-16, pp. 1801-1811, 2009.

[18] J. F. Martín, R. V. Ullán, and C. García-Estrada, "Regulation and compartmentalization of beta-lactam biosynthesis," Microbial Biotechnology, vol. 3, pp. 285-299, 2010.

[19] C. García-Estrada, F. Fierro, and J. F. Martín, "Evolution of fungal $\beta$-lactam biosynthesis gene clusters," in Current Research, Technology and Education Topics in Applied Microbiology and Microbial Biotechnology, A. Mendez-Vilas, Ed., vol. 1, pp. 577-588, Formatex Research Center, Badajoz, Spain, 2010.

[20] K. Kato, "Occurrence of penicillin-nucleus in culture broths," The Journal of Antibiotics, vol. 6, no. 3, pp. 130-136, 1953.

[21] A. L. Demain, "The mechanism of penicillin biosynthesis," Advances in Applied Microbiology, vol. 1, no. C, pp. 23-47, 1959.

[22] F. R. Batchelor, F. P. Doyle, J. H. C. Nayler, and G. N. Rolinson, "Synthesis of penicillin: 6-aminopenicillanic acid in penicillin fermentations," Nature, vol. 183, no. 4656, pp. 257258, 1959.

[23] A. L. Demain and R. P. Blander, "The $\beta$-lactam antibiotics: past, present, and future," Antonie van Leeuwenhoek, vol. 75, no. 1-2, pp. 5-19, 1999.

[24] C. García-Estrada and J. F. Martín, "Penicillins and cephalosporins," in Comprehensive Biotechnology, M. Moo-Young, M. Butler, C. Webb et al., Eds., Elsevier, Amsterdam, The Netherlands, 2nd edition, 2011.

[25] K. B. Raper, D. F. Alexander, and R. D. Coghill, "Penicillin: II. Natural variation and penicillin production in Penicillium notatum and allied species," The Journal of Bacteriology, vol. 48, no. 6, pp. 639-659, 1944.

[26] K. B. Raper, "The development of improved penicillinproducing molds," Annals of the New York Academy of Sciences, vol. 48, pp. 41-56, 1946.

[27] M. P. Backus, J. F. Stauffer, and M. J. Johnson, "Penicillin yields from new mold strains," Journal of the American Chemical Society, vol. 68, no. 1, pp. 152-153, 1946.

[28] M. P. Backus and J. F. Stauffer, "The production and selection of a family of strains in Penicillium chrysogenum," Mycologia, vol. 47, pp. 429-463, 1955.

[29] R. F. Anderson, L. M. Whitmore, W. E. Brown et al., "Production of penicillin by some pigmentless mutants of the mold, Penicillium chrysogenum Q176," Industrial \& Engineering Chemistry, vol. 45, pp. 768-773, 1953.

[30] R. P. Elander, "Strain improvement and preservation of betalactam producing microorganisms," in Antibiotics Containing the Beta-Lactam Structure I, A. L. Demain and N. Solomon, Eds., pp. 97-146, Springer, New York, NY, USA, 1983.

[31] R. P. Elander, "University of Wisconsin contributions to the early development of penicillin and cephalosporin antibiotics," SIM News, vol. 52, pp. 270-278, 2002.

[32] J. Lein, "The Panlabs Penicillium strain improvement program," in Overproduction of Microbial Metabolites, Z. Vanek 
and Z. Hostalek, Eds., pp. 105-140, Butterworths, Stoneham, Mass, USA, 1986.

[33] R. J. Gouka, W. van Hartingsveldt, R. A. L. Bovenberg, C. A. M. J. J. van den Hondel, and R. F. M. van Gorcom, "Cloning of the nitrate-nitrite reductase gene cluster of Penicillium chrysogenum and use of the niaD gene as a homologous selection marker," Journal of Biotechnology, vol. 20, no. 2, pp. 189 199, 1991.

[34] F. Fierro, J. L. Barredo, B. Díez, S. Gutierrez, F. J. Fernández, and J. F. Martín, "The penicillin gene cluster is amplified in tandem repeats linked by conserved hexanucleotide sequences," Proceedings of the National Academy of Sciences of the United States of America, vol. 92, no. 13, pp. 6200-6204, 1995.

[35] M. A. Peñalva, R. T. Rowlands, and G. Turner, "The optimization of penicillin biosynthesis in fungi," Trends in Biotechnology, vol. 16, no. 11, pp. 483-489, 1998.

[36] R. W. Newbert, B. Barton, P. Greaves, J. Harper, and G. Turner, "Analysis of a commercially improved Penicillium chrysogenum strain series: involvement of recombinogenic regions in amplification and deletion of the penicillin biosynthesis gene cluster," Journal of Industrial Microbiology and Biotechnology, vol. 19, no. 1, pp. 18-27, 1997.

[37] M. A. van den Berg, I. Westerlaken, C. Leeflang, R. Kerkman, and R. A. L. Bovenberg, "Functional characterization of the penicillin biosynthetic gene cluster of Penicillium chrysogenum Wisconsin54-1255," Fungal Genetics and Biology, vol. 44, no. 9, pp. 830-844, 2007.

[38] F. Fierro, C. García-Estrada, N. I. Castillo, R. Rodriguez, T. Velasco-Conde, and J. F. Martín, "Transcriptional and bioinformatic analysis of the $56.8 \mathrm{~kb}$ DNA region amplified in tandem repeats containing the penicillin gene cluster in Penicillium chrysogenum," Fungal Genetics and Biology, vol. 43, pp. 618-629, 2006.

[39] C. García-Estrada, I. Vaca, M. Lamas-Maceiras, and J. F. Martín, "In vivo transport of the intermediates of the penicillin biosynthetic pathway in tailored strains of Penicillium chrysogenum," Applied Microbiology and Biotechnology, vol. 76, pp. 169-182, 2007.

[40] K. Kosalková, C. García-Estrada, and R. V. Ullán, “The global regulator LaeA controls penicillin biosynthesis, pigmentation and sporulation, but not roquefortine C synthesis in Penicillium chrysogenum," Biochimie, vol. 91, pp. 214-225, 2009.

[41] B. Hoff, J. Kamerewerd, C. Sigl et al., "Two components of a velvet-like complex control hyphal morphogenesis, conidiophore development, and penicillin biosynthesis in Penicillium chrysogenum," Eukaryotic Cell, vol. 9, no. 8, pp. 1236 1250, 2010.

[42] C. Sigl, H. Haas, T. Specht, K. Pfaller, H. Kurnsteiner, and I. Zadra, "Among developmental regulators, StuA but not BrlA is essential for penicillin V production in Penicillium chrysogenum," Applied and Environmental Microbiology, vol. 77, pp. 972-982, 2011.

[43] C. García-Estrada, R. V. Ullán, T. Velasco-Conde et al., "Posttranslational enzyme modification by the phosphopantetheinyl transferase is required for lysine and penicillin biosynthesis but not for roquefortine or fatty acid formation in Penicillium chrysogenum," Biochemical Journal, vol. 415, pp. 317-324, 2008.

[44] M. Lamas-Maceiras, I. Vaca, E. Rodríguez, J. Casqueiro, and J. F. Martín, "Amplification and disruption of the phenylacetylCoA ligase gene of Penicillium chrysogenum encoding an arylcapping enzyme that supplies phenylacetic acid to the isopenicillin N-acyltransferase," Biochemical Journal, vol. 395, no. 1, pp. 147-155, 2006.
[45] D. J. Smith, J. H. Bull, J. Edwards, and G. Turner, "Amplification of the isopenicillin $\mathrm{N}$ synthetase gene in a strain of Penicillium chrysogenum producing high levels of penicillin," Molecular and General Genetics, vol. 216, no. 2-3, pp. 492497, 1989.

[46] J. G. Nijland, B. Ebbendorf, M. Woszczynska, R. Boer, R. A. L. Bovenberg, and A. J. M. Driessen, "Nonlinear biosynthetic gene cluster dose effect on penicillin production by Penicillium chrysogenum," Applied and Environmental Microbiology, vol. 76, no. 21, pp. 7109-7115, 2010.

[47] R. Smidák, M. Jopcík, M. Kralovicová et al., "Core promoters of the penicillin biosynthesis genes and quantitative RT-PCR analysis of these genes in high and low production strain of Penicillium chrysogenum," Folia Microbiologica, vol. 55, pp. 126-132, 2010.

[48] J. M. Fernández-Cañón and M. A. Peñalva, "A fungal model for inborn errors in human phenylalanine metabolism," Proceedings of the National Academy of Sciences of the United States of America, vol. 92, pp. 9132-9136, 1995.

[49] J. M. Mingot, M. A. Peñalva, and J. M. Fernández-Cañón, "Disruption of phacA, an Aspergillus nidulans gene encoding a novel cytochrome P450 monooxygenase catalyzing phenylacetate 2-hydroxylation, results in penicillin overproduction," Journal of Biological Chemistry, vol. 274, no. 21, pp. 14545-14550, 1999.

[50] E. Arias-Barrau, E. R. Olivera, J. M. Luengo et al., "The homogentisate pathway: a central catabolic pathway involved in the degradation of L-phenylalanine, L-tyrosine, and 3hydroxyphenylacetate in Pseudomonas putida," The Journal of Bacteriology, vol. 186, pp. 5062-5077, 2004.

[51] F. Ferrer-Sevillano and J. M. Fernández-Cañón, "Novel phacB-encoded cytochrome P450 monooxygenase from Aspergillus nidulans with 3-hydroxyphenylacetate 6-hydroxylase and 3,4-dihydroxyphenylacetate 6-hydroxylase activities," Eukaryotic Cell, vol. 6, no. 3, pp. 514-520, 2007.

[52] M. Rodríguez-Sáiz, J. L. Barredo, M. A. Moreno, J. M. Fernández-Cañón, M. A. Peñalva, and B. Díez, "Reduced function of a phenylacetate-oxidizing cytochrome 450 caused strong genetic improvement in early phylogeny of penicillin-producing strains," The Journal of Bacteriology, vol. 183, pp. 5465-5471, 2001.

[53] M. Rodríguez-Sáiz, B. Díez, and J. L. Barredo, "Why did the Fleming strain fail in penicillin industry?" Fungal Genetics and Biology, vol. 42, no. 5, pp. 464-470, 2005.

[54] J. A. K. W. Kiel, I. J. van der Klei, M. A. van den Berg, R. A. L. Bovenberg, and M. Veenhuis, "Overproduction of a single protein, Pc-Pex11p, results in 2-fold enhanced penicillin production by Penicillium chrysogenum," Fungal Genetics and Biology, vol. 42, no. 2, pp. 154-164, 2005.

[55] W. H. Müller, T. P. van der Krift, A. J. J. Krouwer et al., "Localization of the pathway of the penicillin biosynthesis in Penicillium chrysogenum," The EMBO Journal, vol. 10, no. 2, pp. 489-495, 1991.

[56] L. Gidijala, I. J. van der Klei, M. Veenhuis, and J. A. K. W. Kiel, "Reprogramming Hansenula polymorpha for penicillin production: expression of the Penicillium chrysogenum pcl gene," FEMS Yeast Research, vol. 7, no. 7, pp. 1160-1167, 2007.

[57] M. A. van den Berg, R. Albang, K. Albermann et al., "Genome sequencing and analysis of the filamentous fungus Penicillium chrysogenum," Nature Biotechnology, vol. 26, pp. 1161-1168, 2008.

[58] W. H. Müller, R. A. L. Bovenberg, M. H. Groothuis et al., "Involvement of microbodies in penicillin biosynthesis," Biochimica et Biophysica Acta, vol. 1116, no. 2, pp. 210-213, 1992. 
[59] W. H. Meijer, L. Gidijala, S. Fekken et al., "Peroxisomes are required for efficient penicillin biosynthesis in Penicillium chrysogenum," Applied and Environmental Microbiology, vol. 76, no. 17, pp. 5702-5709, 2010.

[60] M. A. van den Berg, "Functional characterisation of penicillin production strains," Fungal Biology Reviews, vol. 24, no. 1-2, pp. 73-78, 2010.

[61] D. M. Harris, Z. A. van der Krogt, P. Klaassen et al., "Exploring and dissecting genome-wide gene expression responses of Penicillium chrysogenum to phenylacetic acid consumption and penicillinG production," BMC Genomics, vol. 10, article 75, 2009.

[62] D. Lim, P. Hains, B. Walsh, P. Bergquist, and H. Nevalainen, "Proteins associated with the cell envelope of Trichoderma reesei: a proteomic approach," Proteomics, vol. 1, no. 7, pp. 899-910, 2001.

[63] F. J. Fernández-Acero, I. Jorge, E. Calvo et al., "Two-dimensional electrophoresis protein profile of the phytopathogenic fungus Botrytis cinerea," Proteomics, vol. 6, supplement 1, pp. S88-S96, 2006.

[64] J. V. F. Coumans, P. D. J. Moens, A. Poljak, S. Al-Jaaidi, L. Pereg, and M. J. Raftery, "Plant-extract-induced changes in the proteome of the soil-borne pathogenic fungus Thielaviopsis basicola," Proteomics, vol. 10, no. 8, pp. 1573-1591, 2010.

[65] V. Yildırım, S. Ozcan, D. Becher, K. Buttner, M. Hecker, and G. Ozcengiz, "Characterization of proteome alterations in Phanerochaete chrysosporium in response to lead exposure," Proteome Science, vol. 9, pp. 1-12, 2011.

[66] O. Kniemeyer, F. Lessing, O. Scheibner, C. Hertweck, and A. A. Brakhage, "Optimisation of a 2-D gel electrophoresis protocol for the human-pathogenic fungus Aspergillus fumigatus," Current Genetics, vol. 49, no. 3, pp. 178-189, 2006.

[67] M. Shimizu, T. Fujii, S. Masuo, K. Fujita, and N. Takaya, "Proteomic analysis of Aspergillus nidulans cultured under hypoxic conditions," Proteomics, vol. 9, no. 1, pp. 7-19, 2009.

[68] X. Lu, J. Sun, M. Nimtz, J. Wissing, A. P. Zeng, and U. Rinas, "The intra- and extracellular proteome of Aspergillus niger growing on defined medium with xylose or maltose as carbon substrate," Microbial Cell Factories, vol. 9, article 23, 2010.

[69] M. S. Jami, C. Barreiro, C. García-Estrada, and J. F. Martín, "Proteome analysis of the penicillin producer Penicillium chrysogenum: characterization of protein changes during the industrial strain improvement," Molecular and Cellular Proteomics, vol. 9, no. 6, pp. 1182-1198, 2010.

[70] M. Vödisch, K. Scherlach, R. Winkler et al., "Analysis of the Aspergillus fumigatus proteome reveals metabolic changes and the activation of the pseurotin a biosynthesis gene cluster in response to hypoxia," Journal of Proteome Research, vol. 10, no. 5, pp. 2508-2524, 2011.

[71] R. Cobos, C. Barreiro, R. M. Mateos, and J. R. Coque, "Cytoplasmic- and extracellular-proteome analysis of Diplodia seriata: a phytopathogenic fungus involved in grapevine decline," Proteome Science, vol. 8, article 46, 2010.

[72] Y. T. Oh, C. S. Ahn, J. G. Kim, H. S. Ro, C. W. Lee, and J. W. Kim, "Proteomic analysis of early phase of conidia germination in Aspergillus nidulans," Fungal Genetics and Biology, vol. 47, no. 3, pp. 246-253, 2010.

[73] V. Bhadauria, W. S. Zhao, L. X. Wang et al., "Advances in fungal proteomics," Microbiological Research, vol. 162, no. 3, pp. 193-200, 2007.

[74] C. Barreiro, E. Gonzalez-Lavado, S. Brand, A. Tauch, and J. F. Martín, "Heat shock proteome analysis of wild-type Corynebacterium glutamicum ATCC 13032 and a spontaneous mutant lacking GroEL1, a dispensable chaperone," The Journal of Bacteriology, vol. 187, no. 3, pp. 884-889, 2005.
[75] D. W. Kim, K. Chater, K. J. Lee, and A. Hesketh, "Changes in the extracellular proteome caused by the absence of the bldA gene product, a developmentally significant tRNA, reveal a new target for the pleiotropic regulator AdpA in Streptomyces coelicolor," The Journal of Bacteriology, vol. 187, no. 9, pp. 2957-2966, 2005.

[76] G. Candiano, M. Bruschi, L. Musante et al., "Blue silver: a very sensitive colloidal Coomassie G-250 staining for proteome analysis," Electrophoresis, vol. 25, no. 9, pp. 1327-1333, 2004.

[77] M. M. Bradford, "A rapid and sensitive method for the quantitation of microgram quantities of protein utilizing the principle of protein dye binding," Analytical Biochemistry, vol. 72, no. 1-2, pp. 248-254, 1976.

[78] J. Ohnishi, M. Hayashi, S. Mitsuhashi, and M. Ikeda, "Efficient 40 degrees $\mathrm{C}$ fermentation of L-lysine by a new Corynebacterium glutamicum mutant developed by genome breeding," Applied Microbiology and Biotechnology, vol. 62, no. 1, pp. 69-75, 2003.

[79] B. L. Gómez and J. D. Nosanchuk, "Melanin and fungi," Current Opinion in Infectious Diseases, vol. 16, no. 2, pp. 91-96, 2003.

[80] R. J. Kleijn, F. Liu, W. A. van Winden, W. M. van Gulik, C. Ras, and J. J. Heijnen, "Cytosolic NADPH metabolism in penicillin-G producing and non-producing chemostat cultures of Penicillium chrysogenum," Metabolic Engineering, vol. 9, no. 1, pp. 112-123, 2007.

[81] U. Nasution, W. M. van Gulik, C. Ras, A. Proell, and J. J. Heijnen, "A metabolome study of the steady-state relation between central metabolism, amino acid biosynthesis and penicillin production in Penicillium chrysogenum," Metabolic Engineering, vol. 10, no. 1, pp. 10-23, 2008.

[82] Y. Hadas, I. Goldberg, O. Pines, and D. Prusky, "Involvement of gluconic acid and glucose oxidase in the pathogenicity of Penicillium expansum in apples," Phytopathology, vol. 97, no. 3, pp. 384-390, 2007.

[83] C.-S. Hwang, M. A. Flaishman, and P. E. Kolattukudy, "Cloning of a gene expressed during appressorium formation by Colletotrichum gloeosporioides and a marked decrease in virulence by disruption of this gene," Plant Cell, vol. 7, no. 2, pp. 183-193, 1995.

[84] S. M. Beverley, K. L. Owens, M. Showalter et al., "Eukaryotic UDP-galactopyranose mutase (GLF Gene) in microbial and metazoal pathogens," Eukaryotic Cell, vol. 4, no. 6, pp. 11471154, 2005.

[85] M. Machida, K. Asai, M. Sano et al., "Genome sequencing and analysis of Aspergillus oryzae," Nature, vol. 438, no. 7071, pp. 1157-1161, 2005.

[86] H. J. Pel, J. H. de Winde, D. B. Archer et al., "Genome sequencing and analysis of the versatile cell factory Aspergillus niger CBS 513.88," Nature Biotechnology, vol. 25, no. 2, pp. 221-231, 2007.

[87] H. Bouws, A. Wattenberg, and H. Zorn, "Fungal secretomes-nature's toolbox for white biotechnology," Applied Microbiology and Biotechnology, vol. 80, no. 3, pp. 381-388, 2008.

[88] A. Steinbüchel, "Nachwachsende rohstoffe für die weiße biotechnologie," in Weiße Biotechnologie-Industrie im Aufbruch, S. Heiden and H. Zink, Eds., pp. 76-91, Biocom AG, Berlin, Germany, 2006.

[89] J. F. Peberdy, "Protein secretion in filamentous fungi-trying to understand a highly productive black box," Trends in Biotechnology, vol. 12, no. 2, pp. 50-57, 1994.

[90] M. S. Jami, C. García-Estrada, C. Barreiro, A. A. Cuadrado, Z. Salehi-Najafabadi, and J. F. Martín, "The Penicillium 
chrysogenum extracellular proteome. Conversion from a food-rotting strain to a versatile cell factory for white biotechnology," Molecular and Cellular Proteomics, vol. 9, no. 12, pp. 2729-2744, 2010.

[91] P. Shah, J. A. Atwood, R. Orlando, H. E. Mubarek, G. K. Podila, and M. R. Davis, "Comparative proteomic analysis of botrytis cinerea secretome," Journal of Proteome Research, vol. 8, no. 3, pp. 1123-1130, 2009.

[92] J. D. Bendtsen, H. Nielsen, G. von Heijne, and S. Brunak, "Improved prediction of signal peptides: signalP 3.0," Journal of Molecular Biology, vol. 340, no. 4, pp. 783-795, 2004.

[93] J. D. Bendtsen, L. J. Jensen, N. Blom, G. von Heijne, and S. Brunak, "Feature-based prediction of non-classical and leaderless protein secretion," Protein Engineering, Design and Selection, vol. 17, no. 4, pp. 349-356, 2004.

[94] J. Choi, J. Park, D. Kim, K. Jung, S. Kang, and Y. H. Lee, "Fungal secretome database: integrated platform for annotation of fungal secretomes," BMC Genomics, p. 105, 2010.

[95] G. Lum and X. J. Min, "FunSecKB: the fungal secretome knowledgeBase," Database, vol. 2011, pp. 1-10, 2011.

[96] C. J. Jeffery, "Moonlighting proteins," Trends in Biochemical Sciences, vol. 24, no. 1, pp. 8-11, 1999.

[97] W. Nickel, "The mystery of nonclassical protein secretion: a current view on cargo proteins and potential export routes," European Journal of Biochemistry, vol. 270, no. 10, pp. 21092119, 2003.

[98] W. Nickel, "Unconventional secretory routes: direct protein export across the plasma membrane of mammalian cells," Traffic, vol. 6, no. 8, pp. 607-614, 2005.

[99] W. Nickel and C. Rabouille, "Mechanisms of regulated unconventional protein secretion," Nature Reviews Molecular Cell Biology, vol. 10, no. 2, pp. 148-155, 2009.

[100] J. A. Simpson and E. S. C. Weiner, The Compact Oxford English Dictionary, Oxford University Press, New York, NY, USA, 2nd edition, 1992.

[101] C. Gancedo and C. L. Flores, "Moonlighting proteins in yeasts," Microbiology and Molecular Biology Reviews, vol. 72, no. 1, pp. 197-210, 2008.

[102] C. L. Flores and C. Gancedo, "Unraveling moonlighting functions with yeasts," IUBMB Life, vol. 63, no. 7, pp. 457-462, 2011.

[103] J. A. K. W. Kiel, M. A. van den Berg, F. Fusetti et al., "Matching the proteome to the genome: the microbody of penicillinproducing Penicillium chrysogenum cells," Functional and Integrative Genomics, vol. 9, no. 2, pp. 167-184, 2009.

[104] M. Oku and Y. Sakai, "Peroxisomes as dynamic organelles: autophagic degradation,” The FEBS Journal, vol. 277, no. 16, pp. 3289-3294, 2010.

[105] C. A. Cantwell, R. J. Beckmann, J. E. Dotzlaf et al., “Cloning and expression of a hybrid Streptomyces clavuligerus cefE gene in Penicillium chrysogenum," Current Genetics, vol. 17, no. 3, pp. 213-221, 1990.

[106] R. V. Ullán, S. Campoy, J. Casqueiro, F. J. Fernandez, and J. F. Martín, "Deacetylcephalosporin C production in Penicillium chrysogenum by expression of the isopenicillin $\mathrm{N}$ epimerization, ring expansion, and acetylation genes," Chemistry \& Biology, vol. 14, pp. 329-339, 2007.

[107] D. M. Harris, I. Westerlaken, D. Schipper et al., "Engineering of Penicillium chrysogenum for fermentative production of a novel carbamoylated cephem antibiotic precursor," Metabolic Engineering, vol. 11, pp. 125-137, 2009.

[108] J. M. Cantoral, S. Gutiérrez, F. Fierro, S. Gil-Espinosa, H. van Liempt, and J. F. Martín, "Biochemical characterization and molecular genetics of nine mutants of Penicillium chrysogenum impaired in penicillin biosynthesis," Journal of Biological Chemistry, vol. 268, no. 1, pp. 737-744, 1993.

[109] N. Yamashita, T. Motoyoshi, and A. Nishimura, "Purification and characterization of isoamyl alcohol oxidase ("Mureka"forming enzyme)," Bioscience, Biotechnology, and Biochemistry, vol. 63, pp. 1216-1222, 1999.

[110] H. E. Swaisgood, V. G. Janolino, and P. J. Skudder, "Continuous treatment of ultrahigh-temperature sterilized milk using immobilized sulfhydryl oxidase," Methods in Enzymology, vol. 136, no. C, pp. 423-431, 1987.

[111] Y. Kodama, Y. Nakao, and T. Shimonaga, "Dihydroxy-acid dehydratase gene and use thereof ," USPTO Patent Application 20090148555, 2009.

[112] Y. Fuke, S. Kaminogawa, H. Matsuoka, and K. Yamauchi, "Purification and properties of aminopeptidase I from Penicillium caseicolum," Journal of Dairy Science, vol. 71, pp. 1423-1431, 1988.

[113] M. Srinivasan, A. R. Sudheer, and V. P. Menon, "Ferulic acid: therapeutic potential through its antioxidant property," Journal of Clinical Biochemistry and Nutrition, vol. 40, no. 2, pp. 92-100, 2007.

[114] T. Koseki, S. Fushinobu, Ardiansyah, H. Shirakawa, and M. Komai, "Occurrence, properties, and applications of feruloyl esterases," Applied Microbiology and Biotechnology, vol. 84, pp. 803-810, 2009. 

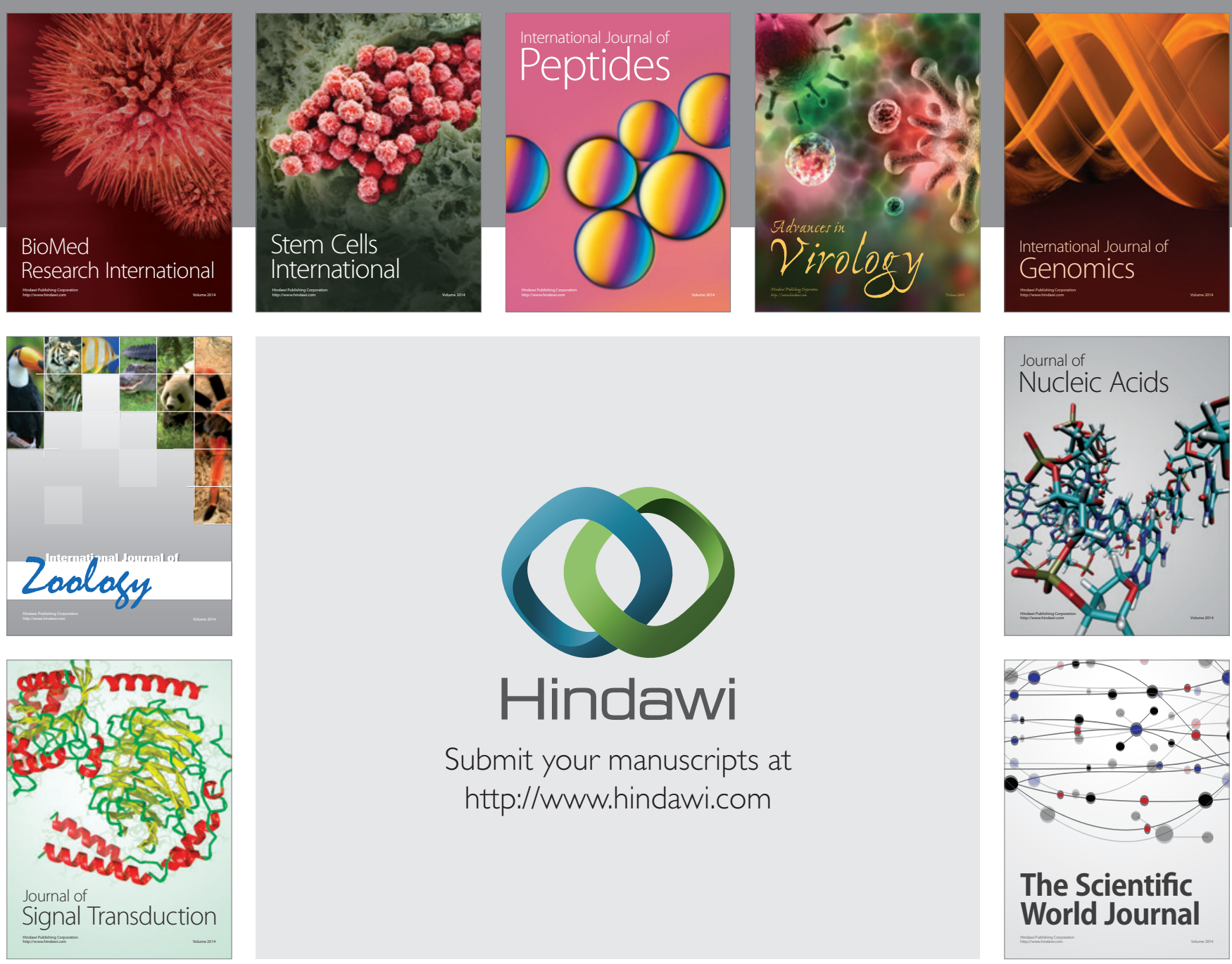

Submit your manuscripts at

http://www.hindawi.com
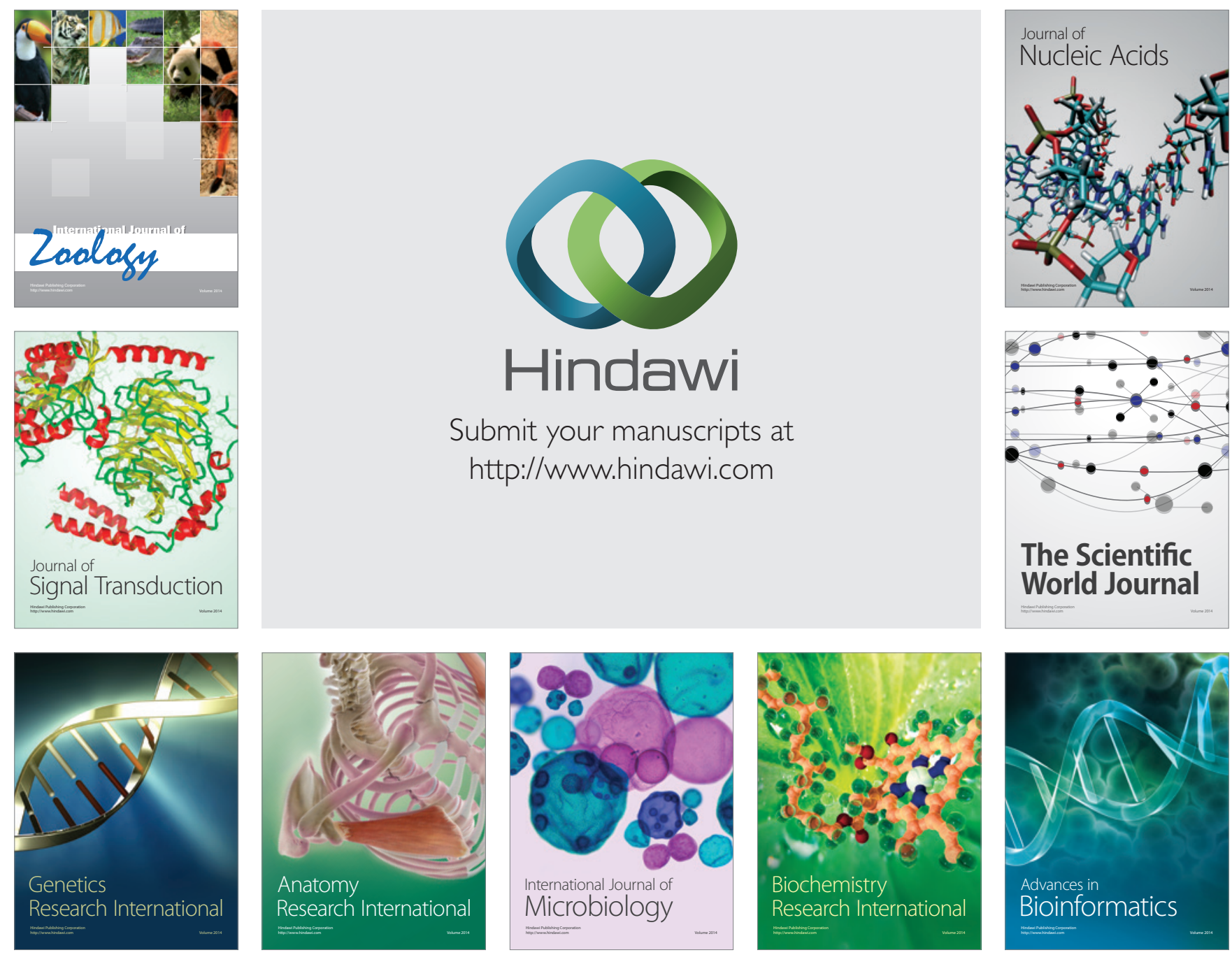

The Scientific World Journal
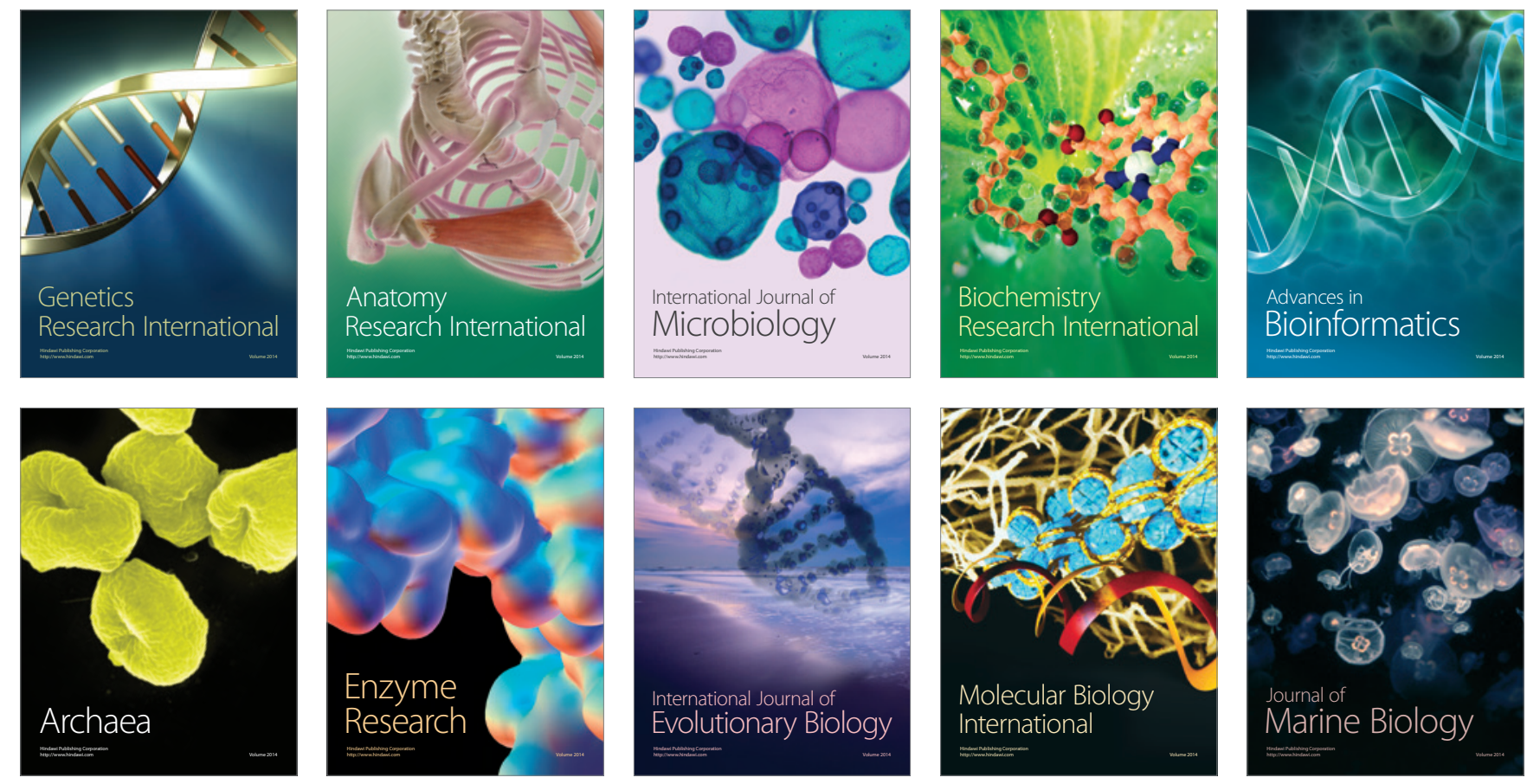